\title{
Banks' business strategies on the edge of distress
}

\author{
Andrea Flori $^{1} \cdot$ Simone Giansante ${ }^{2}$ (D) $\cdot$ Claudia Girardone $^{3} \cdot$ Fabio Pammolli $^{1}$ \\ Published online: 24 September 2019 \\ (c) The Author(s) 2019
}

\begin{abstract}
The paper investigates the importance of banks' business classification in shaping the risk profile of financial institutions on a global scale. We employ a rare-event logit model based on a state-of-the-art list of major global distress events from the global financial crisis. When clustering banks by their business strategies using a community detection approach, we show that (i) capital enhanced resilience only for traditional banks that were on average less capitalized than other banks; (ii) boosting ROE, usually associated with riskier exposures, improved resilience for stable funded and asset diversified banks; (iii) conversely, higher levels of ROA exacerbated banks' vulnerability when associated with concentrated (notdiversified) investment structures; (iv) size in terms of total assets contributed to instability only for wholesale-funded institutions due to their high levels of unstable funding. Liquidity, on the contrary, reduced the institution likelihood of being in distress, regardless of its business classification. Although our findings refer to the recent financial crisis, they provide evidence that a tailored risk monitoring based on a proper peer group identification can facilitate banks' distresses prediction.
\end{abstract}

Keywords Bank business strategies · Clustering $\cdot$ Bank distress $\cdot$ Financial crisis

JEL Classification F01 · G01 · G21 · G28 · G33

Simone Giansante

S.Giansante@bath.ac.uk

Andrea Flori

andrea.flori@polimi.it

Claudia Girardone

cgirard@essex.ac.uk

Fabio Pammolli

fabio.pammolli@polimi.it

1 Department of Management, Economics and Industrial Engineering, Polytechnic University of Milan, Milan, Italy

2 University of Bath - School of Management, Bath, UK

3 University of Essex - Essex Business School, Colchester, UK 


\section{Introduction}

The transition from traditional to modern banking with the implementation of the so-called "universal banking model"1 allowed banks to expand, over the past three decades, their traditional and specialized business strategies to a wider range of products and services, including security/investment banking and wholesale-debt. Hence, the constellation of possible combinations of asset-liability choices at the banks disposal makes the classification of their business strategies a complex task. This ultimately limits the ability of regulators to tailor risk monitoring to the specific vulnerability of each strategy to distress. ${ }^{2}$

Although there is no strong evidence to support the claim that universal banks are riskier than specialized ones (Benston 1994; Cornett et al. 2002; Dietrich and Vollmer 2012; Curi et al. 2015), some studies (e.g., Demirgüc-Kunt and Huizinga 2010; Lozano-Vivas and Pasiouras 2010) show a non-monotonic impact of non-traditional funding-investment models on risk. Starting from low level of non-deposit funding in combination with non-interest income activities, these non-traditional banking strategies provide risk diversification benefits, whereas further increases in the level of this mix amplify bank fragility. ${ }^{3}$ Consider for example the impact of leverage growth, that is typically associated with a higher level of risk. On one side, leverage could improve resilience for deposit-funded banks as it will boost their stable funding. On the other side, it could also increase bank vulnerability if associated with a very specialized investment strategy that suffers from the lack of diversification. The universal model offers better diversification opportunities that usually facilitate resilience (Dietrich and Vollmer 2012), although sources of funding towards wholesale-debt tend to exacerbate distress during market crisis due to the low levels of stable funding.

This paper relates to the growing debate on the importance of banks business model classification and its impact on performance and risk (Hryckiewicz and Kozłowski 2017; Martin-Oliver et al. 2017; Lucas et al. 2018). We focus on the interplay between assets and liabilities to propose the detection of stylized banking business strategies, which are interpreted as the combinations of funding and investment choices that unravel the core drivers of their business models.

To classify banks into strategy groups according to their business features, we implement a clustering technique designed for high-dimensional and sparse data sets, like accountingbased data. Then, we test whether those competitive business strategies identified by the clustering detection are exposed to different risk drivers. Finally, we provide insights on how to accurately signal business strategy instability. We are interested in exposing the vulnerability of banking business strategies to the likelihood of distress, which can help regulators to design ex-ante solutions to restore resilience.

\footnotetext{
${ }^{1}$ This model was formally introduced in the EU by the Second Banking Directive in 1992, in the US via the Gramm-Leach-Bliley Act in 1999 and in Japan by the "Japanese Big Bang" financial reforms in 1990s (Casu et al. 2015; Hoshi and Kashyap 1999). Banks operating in emerging markets have also been subject to widespread financial deregulation and innovation that have impacted their business strategies as shown e.g. in Hawkins and Mihaljek (2001).

2 The Supervisory Review and Evaluation Process (SREP) put in place in Europe (EBA 2014) is a direct example of incorporating business models characteristics for accurate banks' peer group analysis as an important pillar for monitoring the banking sector's stability and soundness.

${ }^{3}$ Even though risk diversification can be beneficial at the institution level to reduce its probability of default, diversification at a large scale could eventually increase the similarity among institutions, increasing the probability of joint failures with dangerous systemic consequences (Wagner 2010). The so-called dark side of diversification can be avoided by securitization, offering non-linear diversification strategies via tranches of portfolio investments (van Oordt 2013).
} 
Using a large set of bank level indicators of business strategies from 2005 to 2014, we identify three dominant and very popular peer groups each corresponding to a combination of business strategies that were stable over the whole period under investigation. The first, labelled $A$, is characterized by a universal banking model with dominant wholesale funding and diversified loans investments. Group $B$ is an hybrid model that combines wholesale funding from modern banking with specialized investments in commercial loans, common in traditional banking. Group $C$ follows a traditional banking model focused on deposit funding and commercial loans investments. Two other groups, less popular than the three core ones, were also available prior to the financial crisis, named $D$ and $E$. The former resembles group $C$ with more long-term wholesale funding, whereas the latter is another hybrid model with wholesale funding and specialized investments in retail loans. ${ }^{4}$

We then test whether the identified peer groups show different risk drivers during the recent global financial crisis. Due to the magnitude of the 2008 financial crisis, we construct a global distress events list by merging signals regarding bankruptcies and liquidations, defaults, distressed mergers and public bailouts. We then follow the literature (see e.g., Betz et al. 2014; Vazquez and Federico 2015) which examine the impact of these major events and regress them against financial ratios after controlling for macro and sectoral effects, but differently from previous works we apply a rare-event logit model to take into account the possibility of a small amount of distress events compared to the size of the sample.

Although all groups were prone to the risk of distress at the outbreak of the financial crisis, we find different risk drivers when controlling for strategy group membership. The size of the institution (see e.g., Wang 2015), measured in terms of total assets, is positively related to the likelihood of distress only in the wholesale-funded groups, suggesting a higher vulnerability of large institutions adopting strategies with a much lower proportion of stable funding than the deposit-oriented group. Higher capital over total assets, i.e. lower leverage, contributes to limit the likelihood of distress only for deposit-funded banks. Besides, in our sample these latter appear less capitalized on average than wholesale-funded banks, suggesting that recapitalizations had a relatively limited impact on those modern banks that, due to their risky exposures, were already holding comparatively higher levels of capital.

However, changes in leverage can directly affect ROA and ROE, with indirect consequences to bank resilience. When looking at those drivers individually, we observe that ROA impacted positively the risk of distress for deposit-funded groups, and negatively for the wholesale ones. This implies that the limited assets diversification strategies of the traditional deposit-funded institutions can force them to concentrate their investments on fewer products in the pursuit of higher assets returns, generating an overall riskier profile compared to the wholesale-funded groups. In contrast, results for ROE suggest that leverage may intensify stable funding in the case of deposit-funded groups, hence improving their resilience, while wholesale-funded groups would pay the price of more unstable non-deposit funding growth in the pursuit of higher ROE. The notable exception is liquidity, whose impact on the risk of distress is significantly negative and this result is consistent across all business models. This suggests a positive contribution of liquidity to resilience which appears exogenous to the strategy group choice (Tirole 2011). Overall, although the above evidence refers to the period of the global financial crisis, it lends support to our premises that a targeted policy intervention based on business strategy classification may facilitate the prediction of banks' distress.

\footnotetext{
4 Finally, two remaining post crisis groups, labelled $F$ and $G$, identify a deposit-funded strategy with diversified loan investments and an investment banking model with both high non-deposit funding and non-interest based investments, respectively. Note that the empirical exercise in this study focuses on the pre-crisis strategies only, therefore results for these post-crisis groups are available from the authors upon request.
} 
The paper is organized as follows. Section 2 presents the relevant literature on banks' business models classification. Section 3 describes the data sources and main methodological issues, including the construction of our global distress event list and the empirical design. Section 4 presents the cluster approach, validation and the economic features of banks' peer groups. Results are discussed in Sect. 5. Section 6 concludes.

\section{Literature review}

The worst crisis since the Great Depression started roughly two decades after deregulation and financial innovation allowed banks to strategically move from traditional to modern banking. This resulted, among other things, in banks being able to offer a wider range of products and services, hedge derivatives and securitise. Individual banks, however, adapted their strategies to different extent depending on a variety of factors, including their ownership structures, size and risk culture. This paper sets out to determine the resilience of alternative banks' business models appropriately identified using a large global sample and an indirect classification approach. This is a particularly useful analysis for the identification of early warning signals and the prediction of bank distress. The present study contributes to two strands of literature: the first is on clustering techniques and their applications to the banking sector to identify dominant business strategies (Sect. 2.1); and the second one is on the relationship between banks' business models and risk drivers (Sect. 2.2).

\subsection{Selected review of clustering approaches to detect banks' business strategies}

In the literature it is possible to identify two main clustering approaches to derive peer banks groups: (i) a direct, qualitative, approach, provided by the institutions themselves and based for example on bank characteristics such as being listed, mutual and so on ${ }^{5}$; and (ii) an indirect, quantitative, approach that relies on hierarchical clustering methods. ${ }^{6}$ This latter classification is known as the "Ward's method" and employs the Ward (1963)'s procedure to form and identify the distance between the clusters, and includes a stopping rule on the number of clusters based on Caliński and Harabasz (1974).

Literature based on the well-known Ward approach exploits balance sheet variables (Ayadi et al. 2011; Roengpitya et al. 2014; Martin-Oliver et al. 2017) to detect similarities and create homogeneous peer groups. These studies test several combinations of assets and liabilities items to characterize banking activities and use Euclidean distances to measure how similar financial institutions are with respect to these dimensions over which banks are supposed to have a direct influence. Income statements characteristics are usually excluded from peer group assessment and identification. ${ }^{7}$ This is because they tend to reflect the interaction between the institution and the market, so they are not under a strong direct control of the

\footnotetext{
5 Bankscope, for instance, distinguishes between 16 main groups/specializations including for example: Bank Holding and Holding Companies, Cooperative Banks, Finance Companies (Credit Card, Factoring and Leasing), Investment Banks, Islamic Banks, Micro-Financing Institutions Private Banking and Asset Management Companies, Real Estate and Mortgage Bank, Savings Bank and Securities Firm.

6 Clustering methods are also used for outlier detection as, for instance, in Duan et al. (2009).

7 An exception is presented in Puliga et al. (2016).
} 
institution itself. Those characteristics are, however, part of the CAMELS rating framework used by supervisors to capture banks' overall risk condition. ${ }^{8}$

The direct approach has been used in number of studies, such as Demirgüc-Kunt and Huizinga (2010), and more recently (Köhler 2015). These authors document evidence of a non-monotonic effect of non-traditional banking activities to risk employing a direct classification of listed versus unlisted banks. The narrow focus of these studies on the identification of banks' business models motivates our goal to go beyond the usual distinction based on ownership structure and extend the sample to all global institutions for which relevant data are available.

An indirect classification of large EU banks is provided by e.g. Roengpitya et al. (2014) and Ayadi and De Groen (2015). The latter study finds clear distinctions between retail-oriented models, characterized by the traditional customer deposit-loan intermediation activity (with different levels of diversification among the groups they identify) and the wholesale and investment models. For these latter, the non-traditional banking activities show a heavy reliance on either interbank lending and funding (wholesale), or trading assets and derivatives (investment). In terms of overall risk profile, retail-oriented models show higher distance to default (measured by the z-score.) ${ }^{9}$ Our classification resembles the models seen above, and provides additional contribution to the literature by extending the sample on a global basis and benefiting from a considerably larger sample coverage (see Sect. 4).

Using a narrow list of balance sheets variables, Roengpitya et al. (2014) implement a similar indirect approach on a sample of top international banks, along with some subjective judgmental elements to filter the final groups. They found three prevailing models adopted globally: retail-funded, wholesale-funded and trading. Retail and wholesale funded models are found to perform better during the period 2006-2014 than trading model, while retail banks show more volatility in their performance compared to wholesale institutions. The same cluster analysis is also performed by Martin-Oliver et al. (2017) to investigate the banking crisis in Spain across institutions with different business models, ownership and governance features.

Alternative approaches to business model classifications adopt time series clustering as proposed by Mergaerts and Vander Vennet (2016) and, more recently, Lucas et al. (2018). ${ }^{10}$ Mergaerts and Vander Vennet (2016) propose a continuous type classification method to discover peer groups by employing a factor analysis. However, this approach only provides a description of the peer groups that better explain the variables set without a direct link to the individual institutions adopting that business model. This is an important limitation that would make any direct intervention by the regulators problematic. Lucas et al. (2018) identify six main dimensions characterizing banks' business models: size, funding, activity, complexity, geography and ownership. Their advantage compared to cross-sectional setups lies on the ability to control for both cross-section and time varying properties of business models. However, their approach is limited to the dynamics of the clusters overtime with

\footnotetext{
8 CAMELS refers to the six components of a bank's rating system originally developed by US supervisors. It is an acronym that reflects an institution's overall condition, namely: Capital adequacy, Asset quality, Management, Earnings, Liquidity and Sensitivity to market risk (see, for more details, Sect. 3.1). For instance, Cole and White (2012) provide one of the first attempts to study US banks' failures using CAMELS proxies.

9 The z-score is a measure of "distance to insolvency" often used in banking studies, that combines accounting measures of profitability, leverage and volatility. It reflects the number of standard deviations by which returns would have to fall from the mean to wipe out bank equity and is calculated as the sum of equity to total assets and return on average assets (ROAA) scaled by the standard deviation of ROAA.

${ }^{10}$ For optimization literature and use of classifiers systems for bankruptcy prediction, see Ouenniche et al. (2019).
} 
a static composition. This means that institutions are assumed to adopt the same business model over time. Although banks tend to have stable business models, the transition between models is an important indicator of fragility that needs to be considered for accurate risk assessment.

We employ the indirect approach using the Louvain method of community detection (Blondel et al. 2008) that preserves the individual bank classification features and is specifically designed for large, sparse and complex data sets. We also advance on the accuracy of model specifications, which is usually considered a strong point in factor analysis, by relying on a state-of-the-art set of individual bank characteristics on a large sample. Specifically, in this paper we focus on three dimensions to characterize the business strategy of a bank, namely: funding sources, investment activities and the complexity of the strategy. As shown in the methodological section, we also employ a very granular list of bank characteristics.

\subsection{Selected literature on the determinants of bank distress}

There is abundant literature on the balance sheet determinants of bank distress. However, most studies tend to underestimate the importance of defining appropriately business strategies in assessing this relationship. Among the most typical variables that are found to be significantly associated with distress in recent studies are: leverage and capital, liquidity and size.

With emphasis on regulatory capital requirements and liquidity buffers, Vazquez and Federico (2015) claim that high leveraged banks with weak structural liquidity were more likely to default during the 2008-2009 financial crisis. The authors' list of distress events consider the entire set of mergers, while in our study we concentrate on a narrow definition of distressed mergers (Sect. 3.3.1), as also suggested by Betz et al. (2014). Similar findings are reported in Beltratti and Stultz (2012): banks with lower leverage, higher regulatory capital and deposits showed more resilience to distress compared with those high leveraged institutions financed on short-term money markets. Although their analysis covers the precrisis period and only a relatively small sample of banks, they provide a detailed discussion on the resiliance of banks' peer groups based on the mix of asset-liability structures compatible with the universal banking model. Their contribution inspired the set-up for our signal models detailed in Sect. 3.3. The data sample constructed in our study is closely related to Vazquez and Federico (2015) in terms of number of institutions and countries' coverage.

Betz et al. (2014) focus more on the predictability of banks' vulnerability by designing an early warning model for the largest European banks. Using CAMELS rating system as main descriptive elements of banks' risk drivers (see Footnote 8), they develop a signal model on the distress events during the financial crisis by combining both direct bank failures (bankruptcies, liquidations and defaults) with indirect events like state support of distressed institutions and mergers in distress. They show that CAMELS are good indicators of bank distress and that macro-financial imbalances and sectoral indices of vulnerability improve the performance of model predictability. Our study is closely related to Betz et al. (2014) in terms of the use of CAMELS variables as risk drivers and the enlarged set of distress events. Demyanyk and Hasan (2010) offer a detailed review of these models. In our analysis we enrich the data sets described above by considering a larger global sample of banks with a more comprehensive distress events list. Recent work by Mousavi and Ouenniche (2018) provide a useful comparison of corporate distress predictions models. 


\section{Data and methodology}

\subsection{Data}

To carry out the classification of banks' peer groups, we employ data for the immediate pre-crisis period (2005-2007) drawn from the international database Bankscope. We select this specific interval because of data coverage ${ }^{11}$ and to ensure some homogeneity in terms of accounting practices among sampled banks, as the International Financial Reporting Standards (IFRS) became compulsory in Europe for all publicly listed institutions in 2005. In addition, for robustness we extend the classification analysis to 2014 (see Appendix E). To investigate the presence of similarities across institutions in different countries, we consider a global sample covering about 180 countries, of which more than a hundred have at least 10 institutions. Our classification procedure is intended to overcome some of the potential limits due to broad classifications. For this reason, we include all types of peer groups available in Bankscope, except for Central Banks and Specialized Governmental Credit Institutions.

The procedure used to identify peer groups of banks with similar business strategies relies on the characterization of financial institutions by means of balance sheet items. The choice to discard income statement variables is in line with previous literature (e.g., Ayadi et al. 2011; Roengpitya et al. 2014) and reflects the need to identify economic dimensions over which financial institutions can have a direct influence. In our study we exploit a detailed set of balance sheet items for both assets and liabilities, providing a very granular representation of banking activities. The universal model framework has been used to select the list of variables that better represents the main classification of traditional versus modern banking, specifically deposits versus wholesale-debt (from interbank to long term borrowing) on the liability side and traditional versus non-traditional investments (from retail and commercial loans to modern interbank lending and non-interest based investments) on the asset side. Table 1 reports summary statistics of the balance sheet variables used to compute the similarities across financial institutions. The business strategy group detection is done for each year from 2005 to 2014 separately. From the set of institutions to be classified each year, we exclude institutions for which we have less than $1 / 3$ of the selected balance sheet items. To avoid distortions across different sized banks in our global sample, we express each measure as a percentage of the respective total assets.

In the second part of the empirical analysis, to gauge banks' probability of distress we use a wide set of predictors retrieved from several sources. Following the extant literature (see e.g., Flannery 1998; González-Hermosillo 1999), bank-specific features can be expressed in terms of proxies for CAMELS variables, representing our theoretical framework for selecting risk drivers. This representation helps the supervisory authority to identify institutions that need attention. Individual banks' data to construct the CAMELS rating on overall banks' stability are extracted from Bankscope.

In addition, we consider a set of country specific controls for the financial sector as well as macroeconomic conditions (see e.g., Betz et al. 2014; Demirgüç-Kunt and Detragiache 2005; Vazquez and Federico 2015). Since our data set is characterized by a broad classification of financial institutions, we represent the financial sector using a range of variables from classic banking sector indicators (e.g., aggregate non-performing loans to gross loans) to market measures (e.g., the financial sector market returns). Data are retrieved from BIS, Datastream,

11 This is particularly important for the clustering analysis because the selection of balance sheet items aims at preserving a balanced representation of both the assets and the liabilities sides, opting for those variables with the highest coverage among financial institutions. 
Table 1 Balance sheet variables statistics Column Annual Average refers to the average across annual mean values from 2005 to 2014; column Std (Annual Average) shows the standard deviation of annual mean values; column Pool Average indicates the average when observations are pooled across the entire interval 2005-2014; column Pool Std stands for the standard deviation of pooled data; column Annual Average NAs exhibits the average number of missing values computed across annual mean values. Source: Bankscope, authors' own elaborations

\begin{tabular}{|c|c|c|c|c|c|}
\hline Balance sheet items & Annual average & SD & Pool average & Pool SD & Annual NAs \\
\hline At-equity investments in associates & 0.01 & 0.00 & 0.01 & 0.05 & 3211.60 \\
\hline Available for sale securities & 0.11 & 0.02 & 0.11 & 0.13 & 4563.20 \\
\hline Cash and due from banks & 0.05 & 0.01 & 0.05 & 0.09 & 218.30 \\
\hline Corporate and commercial loans & 0.24 & 0.03 & 0.23 & 0.25 & 4688.80 \\
\hline Customer deposits (current) & 0.29 & 0.02 & 0.29 & 0.24 & 2548.20 \\
\hline Customer deposits (savings) & 0.22 & 0.02 & 0.22 & 0.19 & 5895.00 \\
\hline Customer deposits (term) & 0.28 & 0.02 & 0.28 & 0.25 & 2551.30 \\
\hline Deposits from banks & 0.13 & 0.01 & 0.13 & 0.17 & 2579.90 \\
\hline Derivatives & 0.02 & 0.00 & 0.01 & 0.05 & 7004.50 \\
\hline Fixed assets & 0.02 & 0.00 & 0.02 & 0.04 & 125.40 \\
\hline Held to maturity securities & 0.06 & 0.00 & 0.06 & 0.09 & 6975.30 \\
\hline Loans and advances to banks & 0.15 & 0.01 & 0.15 & 0.17 & 952.30 \\
\hline Other assets & 0.03 & 0.00 & 0.03 & 0.08 & 16.10 \\
\hline Other consumer/retail loans & 0.14 & 0.01 & 0.14 & 0.21 & 7073.20 \\
\hline Other deposits and short-term borrowings & 0.11 & 0.02 & 0.10 & 0.17 & 4854.10 \\
\hline Other funding & 0.04 & 0.00 & 0.04 & 0.11 & 7798.10 \\
\hline Other liabilities & 0.04 & 0.01 & 0.04 & 0.50 & 625.80 \\
\hline Other loans & 0.38 & 0.03 & 0.37 & 0.32 & 1428.50 \\
\hline Other mortgage loans & 0.09 & 0.05 & 0.12 & 0.16 & 9816.60 \\
\hline Other securities & 0.14 & 0.01 & 0.14 & 0.15 & 4641.70 \\
\hline Repos and cash collateral & 0.07 & 0.01 & 0.07 & 0.14 & 9295.20 \\
\hline Reserves for impaired loans & 0.03 & 0.00 & 0.03 & 0.18 & 2819.50 \\
\hline Reserves for pensions and other & 0.01 & 0.00 & 0.01 & 0.02 & 3765.70 \\
\hline Residential mortgage loans & 0.29 & 0.06 & 0.27 & 0.25 & 7453.40 \\
\hline Reverse repos and cash collateral & 0.06 & 0.02 & 0.05 & 0.12 & 9229.50 \\
\hline Senior debt maturing after 1 year & 0.15 & 0.01 & 0.15 & 0.22 & 5749.00 \\
\hline Subordinated borrowing & 0.01 & 0.00 & 0.01 & 0.04 & 5901.00 \\
\hline Total equity & 0.12 & 0.02 & 0.12 & 0.59 & 607.30 \\
\hline Trading securities and at FV through income & 0.05 & 0.01 & 0.04 & 0.11 & 4829.70 \\
\hline
\end{tabular}

The average number of institutions per year is about 10,400. Data for each institution are standardized by the respective total assets

OECD and World Bank. Table 2 provides the full list and the specific data sources. Table 10 in Appendix B shows that, with only a few exceptions, correlations among predictors do not exhibit relevant and significant relationships over the period 2005-2007. However, we present different specifications of the baseline model for risk assessment, where we basically test different subsets of predictors to overcome potential issues related to multicollinearity. Results are reported in Appendix F. 
Table 2 Measures, data description and sources This table shows for each predictor its definition and the source from which we retrieved data

\begin{tabular}{|c|c|c|}
\hline Measures & Description & Source \\
\hline Capital & Equity/total assets & Bankscope \\
\hline Capital funding ratio & $($ Common equity + subordinated borrowing $) /$ total assets & Bankscope \\
\hline ROA & Return on average assets & Bankscope \\
\hline ROE & Return on average equity & Bankscope \\
\hline Cost to income ratio & Operating expenses/operating income & Bankscope \\
\hline Net interest margin & Net interest revenues/total earning assets & Bankscope \\
\hline $\begin{array}{l}\text { Interest expenses to } \\
\text { Total liabilities }\end{array}$ & Total interest expenses/total liabilities & Bankscope \\
\hline $\begin{array}{l}\text { Liquid assets to short } \\
\text { Term funding }\end{array}$ & (Cash and other liquid assets)/(Deposits and ST Funding) & Bankscope \\
\hline Deposits to total funding & (Deposits and ST Funding)/Total funding & Bankscope \\
\hline $\begin{array}{l}\text { Total securities to total } \\
\text { Assets }\end{array}$ & Total securities/total assets & Bankscope \\
\hline GDP per capita & Annual percentage growth rate of GDP per capita & World Bank \\
\hline Inflation & Consumer prices (annual \%) & World Bank \\
\hline House price & Real house prices & OECD/BIS \\
\hline Unemployment & $\begin{array}{l}\text { Share of the labor force that is without work but available } \\
\text { for and seeking employment }\end{array}$ & World Bank \\
\hline FDI-Inflows & Net inflows (\% of GDP) & World Bank \\
\hline FDI-Outflows & Net outflows (\% of GDP) & World Bank \\
\hline Central Gvt. Debt & $\begin{array}{l}\text { Entire stock of direct government fixed-term contractual } \\
\text { obligations ( } \% \text { of GDP) }\end{array}$ & $\begin{array}{l}\text { World Bank } \\
\text { World Bank }\end{array}$ \\
\hline Gvt. long-term yield & Long-term government bond yield & Datastream \\
\hline $\begin{array}{l}\text { Banks NPLs to Gross } \\
\text { Loans }\end{array}$ & $\begin{array}{l}\text { Domestic financial sector nonperforming loans divided by } \\
\text { the total value of the loan portfolio }\end{array}$ & World Bank \\
\hline Credit to Non-fin Sector & Banks domestic credit to non-financial sector & BIS \\
\hline Market Index & $\begin{array}{l}\text { S\&P Global equity indices (annual \% change) or, } \\
\text { alternatively, FTSE Indices }\end{array}$ & $\begin{array}{l}\text { World Bank/ } \\
\text { Datastream }\end{array}$ \\
\hline Sector Index & FTSE Financial Indices & Datastream \\
\hline Stock traded & $\begin{array}{l}\text { Number of traded shares multiplied by their respective } \\
\text { matching prices }\end{array}$ & World Bank \\
\hline
\end{tabular}

In some specifications of the models we consider aggregated regional proxies for macro and sector measures according to World Bank geographical classifications. Data for House Prices and Credit to Non-financial Sector are on a quarterly basis and then annualized. Data from Datastream are daily and then annualized

\subsection{Clusters detection}

As discussed in Sect. 2.1, a typical benchmark for the cluster analysis of banks' business models is the Ward (1963)'s algorithm combined with the Pseudo-F Index (Caliński and Harabasz 1974) as the stopping rule applied to provide the number of clusters. The PseudoF Index is the ratio of between-cluster variance to within-cluster variance and is used as a metric to assess the quality of the clustering results and to discriminate among different 
specifications of the algorithm setup. In particular, the best configuration, and therefore the resulting number of clusters, is the one associated with the greatest value of the Pseudo-F Index. ${ }^{12}$

In this work, we use a wider list of variables than previous studies and for a larger set of institutions globally distributed. Hence, we prefer to adopt a hierarchical clustering algorithm (namely, the Louvain method) that, although in line with the Ward algorithm, is designed to address the multidimensionality issues in a more appropriate and elegant way for complex and sparse data samples (Lancichinetti et al. 2011; Chakraborty et al. 2013).

In our study, the Louvain classification method relies on the similarities among institutions' financial statement attributes, collected in a vector per bank and per year. To determine these similarities we compute a standard measure used in information retrieval (van Dongen and Enright 2012), namely the cosine similarity, which is typically applied for sparse and multidimensional data (Tan et al. 2006). Hence, we calculate the cosine of the angle between each pair of vectors in the inner product space and we divide it by the vectors' L2 norms to make it bounded between -1 and +1 . Then, the hierarchical Louvain clustering method (Blondel et al. 2008) is applied to the pair-wise similarity matrix to find groups of institutions adopting similar business strategies. These groups are identified by maximizing the modularity quantity, which is a measure that quantifies the strength of division of a system into clusters of densely interconnected institutions that are only sparsely connected with the rest of the system (Newman and Girvan 2004). In our analysis, the resulting clusters represent peer groups of banks sharing similar business strategies. Details of the classification approach are given in Appendix C.

It should be noted that missing values represent a key issue in clustering algorithms whenever authors aim to accommodate the complete data set. The absence of a certain balance sheet item is itself a sign of a business feature and some authors (e.g., Ayadi and De Groen 2015) replace them with zeros. The method proposed in this study does not require ad-hoc assumptions on missing values as by construction the cosine similarity is computed on available data only, providing a more suitable and robust classification for complex and sparse databases like ours.

To test the suitability, or "validation", of the Louvain method we compare in Sect. 4.1 the quality of these clusters with the direct classification provided by Bankscope and the clusters obtained from the Ward algorithm, being aware that it is a complex task with no easy solutions (Han et al. 2011). ${ }^{13}$

\subsection{Empirical approach for risk assessment}

The prediction of banks' distress during the recent financial crisis is performed by means of a logit model on the cross-sectional distribution of three types of variables prior to the global

\footnotetext{
12 This means that those balance sheet items that determine the best configuration may change in time. Therefore, it may be difficult to find a coherent explanation of the emergence of peer groups over time when these groups arise due to balance sheet dimensions that are volatile in number and nature. In addition, the best configuration in Ward is usually associated to a quite small number of variables. By contrast, we believe it is important to consider a richer and detailed list of balance sheet attributes to properly disentangle peer groups. This, in turn, is a further reason on our use of the Louvain method instead of Ward. See Joseph and Bryson (1997) for discussion on the importance of clustering partitions.

13 We also employ non-parametric equality of medians tests (i.e., the Kruskal-Wallis test) to verify whether groups originate from different distributions, along with post-hoc multiple pairwise comparisons (i.e., the Dunn test) to specifically find differences among pairs of groups. We use the Bonferroni correction to take into account the Family-Wise Error Rate, as well as other approaches like Sidak and Holm corrections obtaining similar results. Results are available from the authors upon request.
} 
financial crisis. Specifically, our empirical model is:

$$
\operatorname{Pr}\left(Y_{i}=1 \mid \mathbf{x}_{i}\right)=\Lambda\left(\mathbf{x}_{i} \beta\right)
$$

where $\Lambda$ is a logistic function and $Y_{i}$ assumes value 1 if institution $i$ has been under distressed conditions in the period from 2008 to 2010 and 0 otherwise. Vector $\mathbf{x}$ includes bank-specific measures, financial sector indicators and macro variables. This investigation setup is in line with other works in this literature which aim at disentangling the effects of banks features from the impacts of sectoral and macro controls in the prediction of the likelihood of distress during the recent financial crisis. Given the broad geographical coverage we devote attention in including controls able to map banking and financial sectors worldwide (see Appendix D).

The design of our work intends to identify specific banks features that have different impact to distress due to peer groups membership. Although banks may have changed their business strategies in the expectation of future distress, we believe that the extent of the crisis of 2008 was not properly embedded in banking practices before the effective outbreak of financial markets. However, to limit endogeneity issues, we follow similar investigation frameworks proposed in the literature (see e.g., Manzaneque et al. 2015; Vazquez and Federico 2015) and we exploit the pre-crisis averages (from 2005 to 2007) to compute values of the explanatory variables. $^{14}$

In addition, due to the presence of a few distress events, we decide to apply a rare event logistic regression to take into account the possibility of a small amount of cases of the rarer outcome. In our work, this aspect is particularly relevant when risk assessment models are estimated within peer groups. Hence, to reduce the small-sample bias in the maximum likelihood estimation, we apply the Firth's Penalized-likelihood logistic regression (Firth 1993), which is a convenient approach to obtain finite and consistent estimates of the regression parameters when maximum likelihood procedure suffers from complete or quasi-complete separation. This bias preventive approach imposes priors on model coefficients to limit small sample bias in the $\log$-likelihood regression $\log L^{*}(\beta)=\log L(\beta)+A(\beta)$, where $A(\beta)$ stands for the Jeffreys invariant prior $1 / 2 \log [\operatorname{det}(I(\beta))]$ and $I(\cdot)$ is the Fisher information matrix. To remove the first-order bias of the ML estimates, Firth's correction introduces a term that goes to zero as the sample size increases and counteracts the first-order term from the asymptotic expansion of the bias of the ML estimation. Ma et al. (2013) find, for instance, that Firth's correction is more powerful than score test based meta-analysis and controls type I error well for both balanced and unbalanced studies.

Our risk of distress models rely on proxies for CAMELS dimensions with a wide coverage (see also Table 2 for more details). Among the possible balance sheet indicators, we focus on those that are well-represented over time and across different types of institutions. In particular, capital adequacy is measured by two ratios: equity to assets ratio (as measure of leverage) and the sum of equity plus subordinated borrowings over total assets (Capital Funding Ratio). Capital adequacy represents the level of bank capitalization and higher values stand for better solvency conditions, thus lower values are expected to increase the probability of bank distress. The asset quality is assessed through the return on assets (ROA); in principle, higher returns are negatively related to distressed conditions. The assessment of asset quality within the CAMELS framework usually includes the relationship between loans losses and reserves for impaired loans as an indicator of the quality of the assets side. Due to the relatively poor coverage in our sample for the period prior to the crisis, we rely on $R O A$

\footnotetext{
14 Alternatively, other studies focus on the temporal distance to default (Cole and White 2012) as a balance sheet risk driver used to explain how distress can be affected by the economic cycle (Manzaneque et al. 2015). Note, however, that our pre-crisis period captures the growth phase of the economic cycle and is, therefore, consistent with Manzaneque et al. (2015).
} 
in our main model and then carry out robustness checks for a sub-sample that employs bad loans over total loans. ROA has embedded in the numerator (net income) the contribution of loans losses, while the denominator (total assets) reflects the presence of the corresponding reserves. Appendix F reports our findings for our risk assessment models in which both the capital adequacy and the asset quality are proxied by more accurate, although less available, accounting-based dimensions. For capital adequacy we consider, in fact, the Tier 1 and the Total Capital Ratio, while for asset quality we use Impaired Loans to Gross Loans and Loan Loss Reserves to Impaired Loans. Notwithstanding the sample coverage decreases substantially for these models, we anticipate that the main findings on risk assessment are largely confirmed.

We measure the management quality by means of the return on equity $(R O E)$ and the ratio of operating expenses over operating income (Cost to Income Ratio). The relationships between management quality and the probability of distress is expected to be negative, as better management practices should foster economic performances and institution resilience to distress. Net Interest Margin is utilized as a proxy for earnings and the expected sign of the relationship with distress is negative. In addition, the earnings dimension is approximated by the ratio of Interest Expenses to Total Liabilities and, in this case, the expected relationship is positive. Liquidity is measured by the ratio of liquid assets over customer and short-term funding (Liquid Assets to Short-Term Funding) and by the ratio of deposits and short-term funding over total funding (Deposits to Total Funding). Usually, institutions with better liquidity conditions are more likely to meet their financial obligations and thus are perceived as less risky (Tirole 2011). Finally, the sensitivity to market risk is measured by the share of securities to total assets (Total Securities to Total Assets). The relationship with the probability of distress is ambiguous since securities are a volatile source of income but at the same time can be more liquid than, for example, loans. This feature is particularly relevant for risk assessment during the recent crisis since the effects of fire sales, which represented a channel through which financial distress spread throughout the system, made some institutions more vulnerable. Summary statistics of the predictors' values are shown in Table 3.

Although referring to accounting-based information, CAMELS indicators used in the models for risk distress are not trivially related to the business strategies detected in Sect. 3.2. In fact, (i) CAMELS are not among the indicators used in the multi-dimensional clustering procedure, and (ii) although CAMELS may represent transformation of some indicators used as inputs for the clustering analysis, they are in general strongly representative of the reciprocal influence of both balance sheet and income statement variables, where the latter are excluded from the clustering procedure.

\subsubsection{Distress events definitions}

As described above, the dependent variable $Y_{i}$ in Eq. (1) is a dichotomous variable that takes value 1 if institution $i$ has been under distressed conditions in the period from 2008 to 2010 and 0 otherwise. Table 4 shows the distress events definitions and the corresponding sources that we used to construct this variable.

Institutions may be under distressed conditions due to several reasons, although the recent financial crisis suggests that government bailouts and state aids had a role in the avoidance of systemic crisis and cascade of banks' failures. Therefore, direct failures were quite rare and presenting estimates separately for different distress events would have made the econometric estimation not robust enough. For these reasons, we propose a comprehensive list of distress events which takes into account several definitions of bank distress (for an approach similar 
Table 3 Predictors summary statistics Values are computed as averages over the interval 2005-2007. Source: Authors' own elaborations on data from Bankscope, BIS, Datastream, OECD and World Bank

\begin{tabular}{lccccccc}
\hline & Obs & $q_{0.05}$ & $q_{0.25}$ & Median & Mean & $q_{0.75}$ & $q_{0.95}$ \\
\hline Capital & 7906 & 0.03 & 0.06 & 0.08 & 0.11 & 0.13 & 0.31 \\
Capital funding ratio & 7906 & 0.03 & 0.06 & 0.09 & 0.12 & 0.13 & 0.31 \\
ROA & 7854 & -0.0001 & 0.00 & 0.01 & 0.01 & 0.01 & 0.04 \\
Cost to income ratio & 8376 & 0.35 & 0.56 & 0.66 & 0.65 & 0.74 & 0.89 \\
ROE & 7848 & -0.002 & 0.04 & 0.08 & 0.09 & 0.14 & 0.26 \\
Net interest margin & 7825 & 0.01 & 0.02 & 0.03 & 0.04 & 0.04 & 0.09 \\
Interest expenses to total liabilities & 7769 & 0.002 & 0.02 & 0.02 & 0.03 & 0.03 & 0.07 \\
Liquid assets to short-term funding & 7784 & 0.03 & 0.11 & 0.21 & 0.34 & 0.40 & 0.97 \\
Deposits to total funding & 7857 & 0.52 & 0.84 & 0.96 & 0.88 & 1.00 & 1.00 \\
Total securities to total assets & 8427 & 0.003 & 0.07 & 0.17 & 0.19 & 0.27 & 0.50 \\
GDP per capita & 8509 & 0.01 & 0.02 & 0.03 & 0.03 & 0.03 & 0.08 \\
Inflation & 8274 & 0.00 & 0.02 & 0.02 & 0.03 & 0.03 & 0.10 \\
House Price & 7322 & -0.02 & -0.01 & 0.01 & 0.04 & 0.04 & 0.25 \\
Unemployment & 8464 & 0.04 & 0.05 & 0.07 & 0.07 & 0.10 & 0.10 \\
FDI-Inflows & 8476 & 0.002 & 0.02 & 0.02 & 0.04 & 0.04 & 0.16 \\
FDI-Outflows & 8239 & 0.005 & 0.02 & 0.03 & 0.08 & 0.04 & 0.17 \\
Central Gvt. Debt & 7406 & 0.11 & 0.42 & 0.44 & 0.58 & 0.62 & 1.45 \\
Gvt. long-term yield & 7495 & 0.02 & 0.04 & 0.04 & 0.04 & 0.05 & 0.08 \\
Banks NPLs to gross loans & 8128 & 0.004 & 0.01 & 0.03 & 0.03 & 0.03 & 0.06 \\
Credit to non-financial sector & 7457 & 0.29 & 0.54 & 0.83 & 0.79 & 0.92 & 1.42 \\
Market index & 7769 & 0.07 & 0.07 & 0.17 & 0.21 & 0.28 & 0.50 \\
Sector index & 7466 & 0.09 & 0.20 & 0.20 & 0.31 & 0.26 & 1.32 \\
Stock traded & 7020 & 0.04 & 0.73 & 0.77 & 1.24 & 2.24 & 2.50 \\
\hline For vaiabs & & & & & & &
\end{tabular}

For variables definitions see Sect. 3.1

to ours see Betz et al. (2014) and Vazquez and Federico (2015), while Kick and Koetter (2007) distinguish between different types of distress).

Bankruptcy occurs if the net worth of the bank falls below a country-specific regulatory threshold, while liquidation concerns the sale of bank's assets by the liquidator as per the guidelines of the country regulations and the distribution of the corresponding assets to claimants. These two distress events were quite rare during the recent financial crisis as governments interventions created a safe net to prevent cascade failures. We therefore introduce additional distress definitions to capture these interventions. Defaults occurs if the bank failed to repay interests or principal on its financial obligations beyond any grace period or if some of its instruments are replaced by other obligations at a diminished value as a consequence of a distressed exchange between counterparts. We rely on ratings from Moody's and Standard and Poor's to assess the presence of a default state. In particular, we merge both short-term and long-term ratings and only if the evaluation of the bank conditions is poor in both cases we consider that bank under a default situation. Moreover, forced mergers of distressed institutions have occurred during the crisis. We define an institution as part of a distressed merger if its coverage ratio in $t-1$ was negative. Coverage ratio is a typical indicator used to assess banks' vulnerability conditions (see e.g., González-Hermosillo 


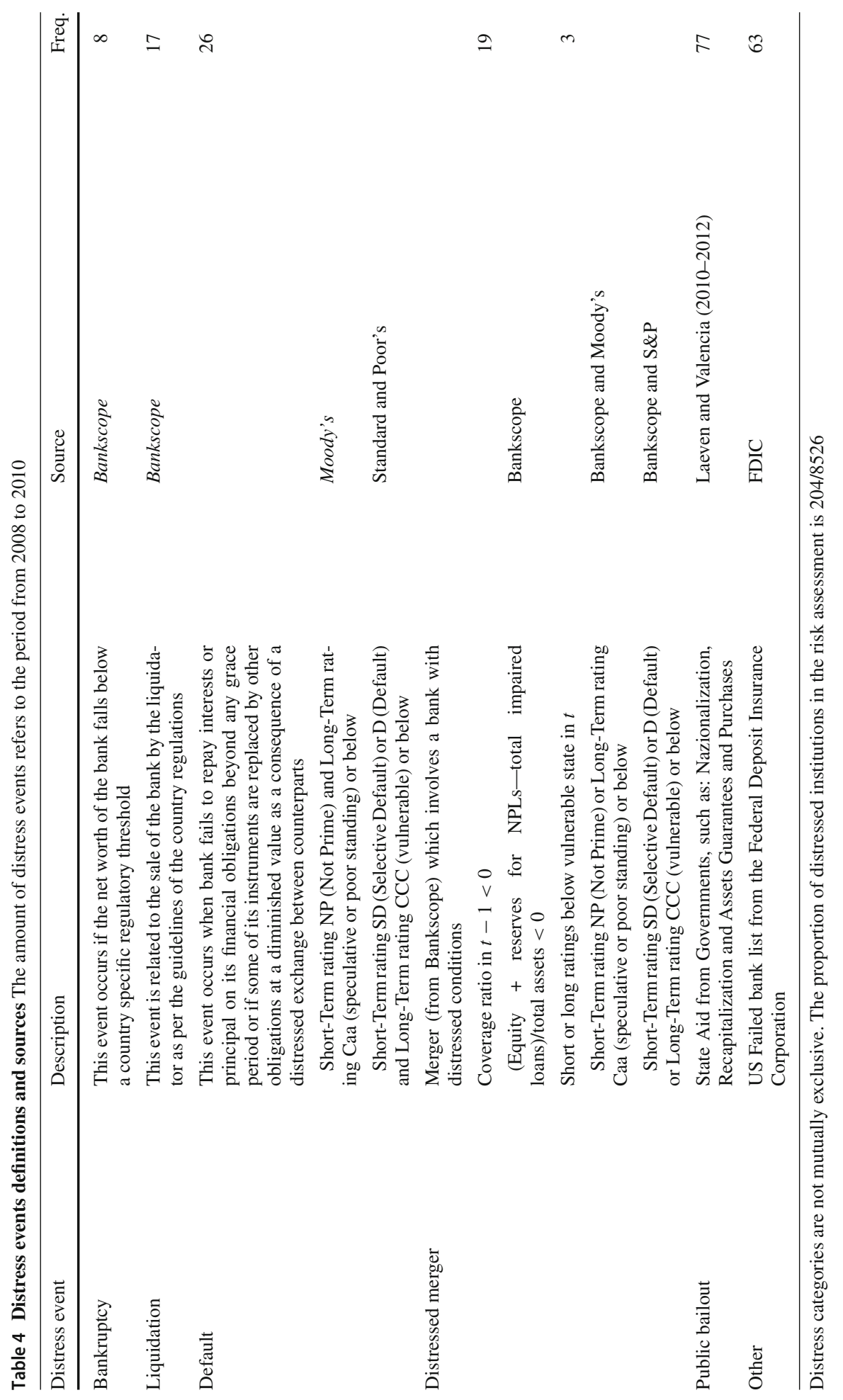


1999) and is computed as the sum of equity plus reserves for non-performing loans minus total impaired loans over total assets. ${ }^{15}$ In addition, we consider as distressed mergers also those cases where the institutions present a rating indicating a vulnerable state. Finally, we enrich the data set of distressed institutions by including the information of public bailouts (Laeven and Valencia 2010, 2012) and, for the US perimeter, we integrate Bankscope with bankruptcy information from the Federal Deposit Insurance Corporation. ${ }^{16}$

The largest proportion of distress events (42\%) occurred by the end of 2008, declining considerably by the end of 2009 (33\%) and 2010 (25\%). However, discriminating distress events by year within the crisis period of 2008-2010 can be misleading as reported, for instance, by Laeven and Valencia (2012). ${ }^{17}$

\section{Banks' business strategies identification and distress events}

\subsection{Clusters validation}

We rely on three main measures for clustering validation, namely the average silhouette width, the Pearson gamma and the average within/between ratio of the distances (see e.g., Halkidi et al. 2001; Han et al. 2011). Note that to clusterize the whole data set of institutions, assumptions aimed at filling missing values, which are of a substantial proportion on a sample size and geographic coverage of this magnitude, have to be considered. Table 5 provides performance measures of each of the three clustering methodologies under four main assumptions for filling missing values: [Z] that assigns zeros to all missing values; [A] that replaces each missing value with the average value across the whole sample for that variable; $[\mathrm{M}]$ similar to the average case but using the medians; $[\mathrm{EM}]$ that estimates missing values using a bootstrap procedure for multiple imputations which combines the Expected Maximization algorithm (Dempster et al. 1977) used to find the mode of the posterior distribution with a bootstrap approach to take draws from this posterior (Honaker and King 2010). Clustering validation measures are computed for the indirect methods and the direct classification (i.e., Bankscope institutions' specializations) using the resulting clusters from the respective approaches and, to enhance comparability, filling missing values using these four criteria separately.

Results confirm that the direct classification is a poor indicator of business strategy assessment, whereas the indirect approaches (both the Louvain adopted in this study and the Ward algorithm) provide superior clustering estimates across different model configurations and validation measures.

Specifically, our evidence indicates that institutions with the same direct specialization may adopt quite different business strategies. Therefore, in line with our expectations, we infer that the direct classification does not provide a sufficiently informative indication of banks' activities, particularly when considering cross-country comparisons. Both Louvain and Ward scores are much higher for the first two statistics and lower for the wb ratio than the direct one by far, supporting the adoption of indirect classifications as better methods to identify banking peer groups. Between the two indirect methods, we observe a very close and

\footnotetext{
15 For the impact of all mergers, not just distressed ones, to distress see Vazquez and Federico (2015).

16 For a study focused on US only, see the ranking-based methods of financial distress proposed by DeYoung and Torna (2013) to reveal the identity of those US troubled institutions reported by FDIC.

17 Due to the complexity of government aids and the timing of their implementation, we follow Laeven and Valencia (2012) definition of the crisis period for consistency.
} 


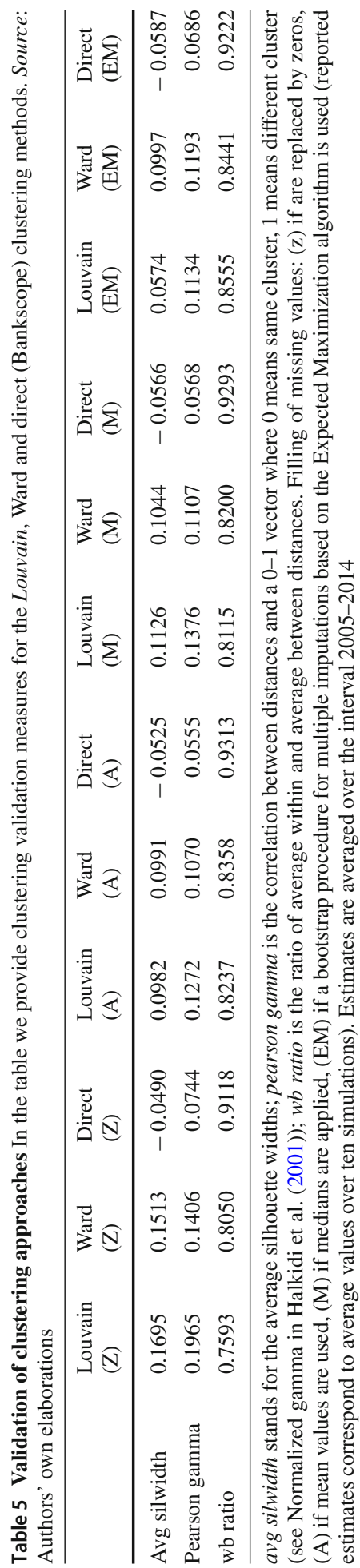


consistent performance across the different model configurations and validation measures. However, we favour the Louvain over the Ward method given the characteristics of our sample and for its advantages when dealing with sparse and complex data.

\subsection{Identification of banks' business strategies}

The aggregate factors used to identify banking business strategies resulting from the cluster analysis are reported in Table 6. Each column represents a business model, where the three dominant or "core" groups that account for the largest number of institutions are labelled as: $A, B$ and $C$. Groups $A$ and $C$ correspond to the two polar cases of wholesale-oriented/modern banks and deposit-oriented/traditional banks, respectively, while group $B$ is a hybrid case in between $A$ and $C .{ }^{18}$ Institutions within these peer groups span well across countries and continents, supporting our empirical setup on a global coverage (details in Appendix D). In some cases, institutions have migrated from one group to the other over the period as discussed in Appendix E.

Group $A$ is is the most popular group in terms of number of institutions (over 3500) and is characterized by the largest proportion of wholesale funding, accounting for roughly $34 \%$ of total assets on average, and well diversified loan investments with moderate exposures to interbank activities. Close similarities are found with the "Wholesale-funded" model discovered in Roengpitya et al. (2014) and the "Wholesale" peer group presented in Ayadi et al. (2012). ${ }^{19}$ Typical institutions in this group have size above average, comparatively low leverage and medium levels of net liquidity. Many US bank holding companiess (e.g., Citigroup) and the top investment banks (e.g., Goldman Sachs), and Russian commercial banks are classified in this group, followed by French (e.g., Société Générale) and Swiss commercial banks (e.g., Credit Swisse).

Group $B$ is characterized by a moderate amount of wholesale funding and the largest exposure to commercial loans investments, which differentiate it from the well diversified group $A$. Institutions in this group tend to be smaller than those in group $A$; they also tend to be highly leveraged and with an appropriate maturity transformation. Their features are similar to the risky "Stakeholder" banks reported in DeYoung and Torna (2013). Group B represents a hybrid peer group similar to group $A$ on the liability side and more traditional on the asset side (similar to group $C$ ). Most of the institutions classified in this model are German (Volksbank and Raiffeisenbank cooperative banks and Sparkasse savings banks) and US-based (mainly regional and state commercial banks). Italy is well represented too in this business model in 2007, with a relatively large number of cooperative along with some commercial and saving banks migrated from the model $D$ discussed below.

\footnotetext{
18 These groups are also consistent in the post-crisis period as reported in Appendix E. To provide a representation of the main features for each peer group, we rely on aggregate variables due to the presence of missing values among the measures used to compute the cosine similarities (Appendix A). When cross checking those variables statistics across different time periods, groups' characteristics appear very stable over time. Since there is inter-temporal stability of institutions within the same cluster (see Table 11 and Appendix E), this evidence confirms our findings of stable membership, thus supporting the interpretation of their features in terms of peer groups.

19 Roengpitya et al. (2014)'s "Wholesale-funded" business model is derived from a much smaller global sample compared to ours. It is characterized by $65.2 \%$ of gross loans and $36.7 \%$ of wholesale debt, along with a $63.1 \%$ stable funding, which are in a similar range as our group $A$. Their interbank composition is slightly less prominent than the one we find for our group A. Ayadi et al. (2012)'s "Wholesale" group is identified using a set of large European banks and is characterized by interbank borrowings and lending $(23.2 \%$ and $16.6 \%$ respectively) very similar to ours. Their Wholesale model tends to be more exposed to non-interest income investments and non-deposit funding compared to ours.
} 


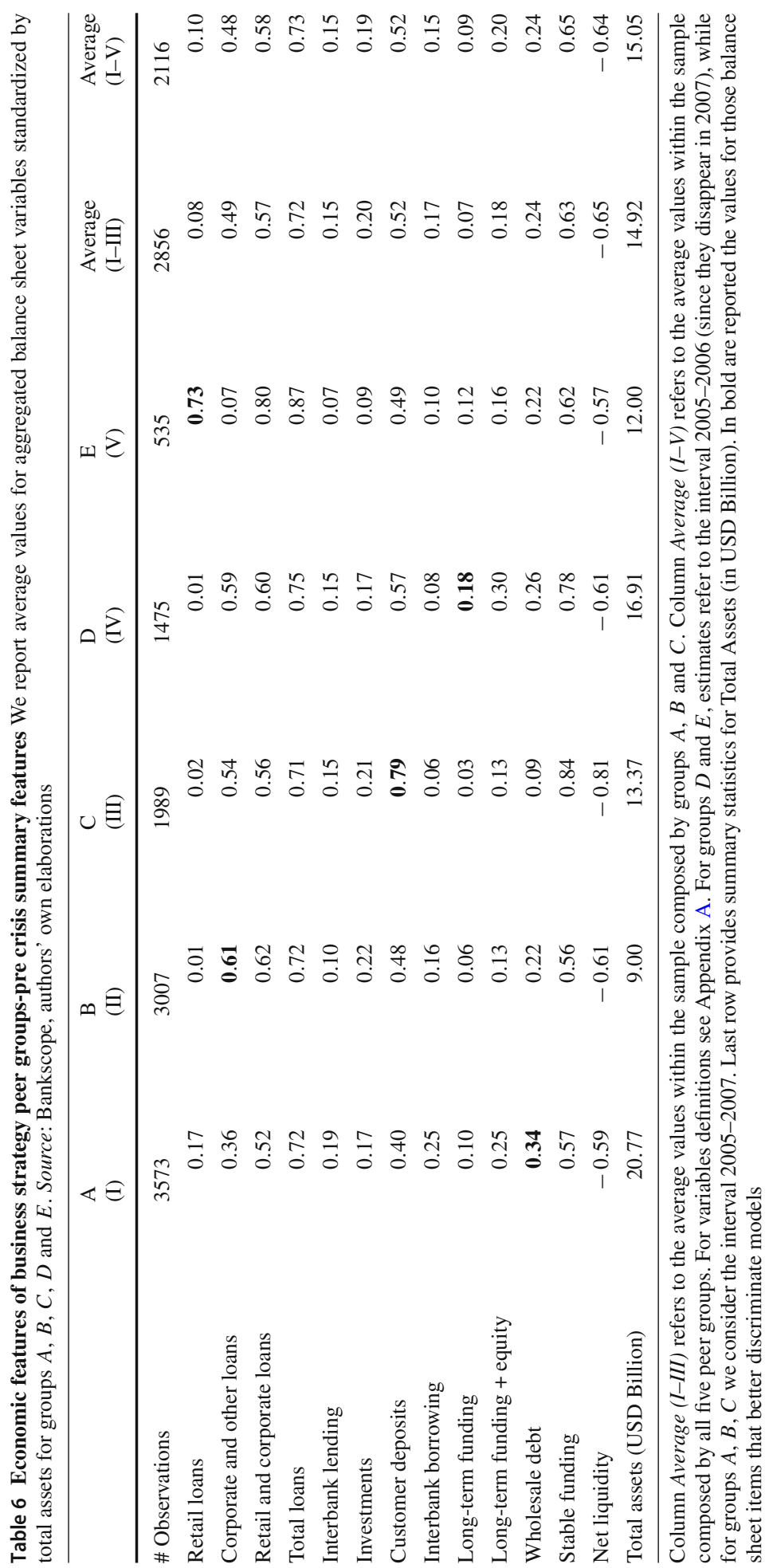


Institutions belonging to the third core peer group $C$ engage primarily on traditional customer deposits funding (the largest across models) and lending activities (mainly commercial loans). They are also the only interbank net lenders among the three core business strategies. In theory, group $C$ provides the most stable funded business strategy due to the deposit-driven liabilities. Roengpitya et al. (2014) find a retail-funded model closely related to our group C. ${ }^{20}$ High leverage, along with dominant commercial loan investments, makes this model very similar to the peer group $B$, although featuring a much more stable funding due to the large proportion of customer deposits to total funding. This is also the business strategy that provides the most dominant maturity transformation of all (the lowest net liquidity value), confirming the provision of traditional banking services. This feature supports the empirical evidence reported in Paligorova and Santos (2016) on the maturity transformation characteristics of wholesale versus deposit-oriented banks. This model is primarily represented by Japanese cooperative banks and US commercial and savings institutions (e.g., Washington Mutual).

Our classification approach also captures two other specialised groups that were prevalent in the first 2 years of our sample and then disappeared at the onset of the crisis. The first, labelled group $D$, accounts for about 1500 institutions, and is characterized by dominant longterm funding, commercial investments and a net interbank lending exposure (as in group $C$ ). Italian and Spanish co-operative and savings banks are the most represented institutions. Most of these institutions migrated to the $B$ peer group in 2007 due to the close similarity with regards to their assets side, with few exceptions migrating to group $C$ (see Appendix E). The second of these specialised business strategies, labelled group $E$, was characterised by a diversified funding combined with the largest exposure to retail loans investments. Those institutions were also highly leveraged compared with the other peer groups. This model was dominated by Swiss saving banks and US bank holdings. At the onset of the crisis most of them migrated to group $A$.

\subsection{Distress events by business strategy}

Table 7 illustrates the distribution of 2008-2010 distress events by peer groups. ${ }^{21}$ Most distress events are found in group $A$, suggesting a fragile business strategy as also reported, for instance, in Ayadi et al. (2011), Demyanyk and Hasan (2010) and Roengpitya et al. (2014). However, generally distress events appear sufficiently well-spread across business strategies. $^{22}$

Our findings offer evidence of a size effect for the wholesale-oriented peer groups as distressed institutions are significantly larger in terms of total assets than their peers. For group $A$, the 64 banks under distress accounted for $\$ 10.5$ tn of total group assets in 2007, 1/6 of the total of their peers, and average sizes of more than $\$ 160 \mathrm{bn}$, almost six times bigger than their peers. Similarly, the 28 distressed institutions in group $B$ reached a total assets

\footnotetext{
${ }^{20}$ Ayadi et al. (2011) find a deposit-oriented group to be net-borrower in the interbank market as opposed to our group $C$; we find this result holds after the crisis. However, their analysis is restricted to European institutions only. In line with our findings for the peer group $C$, Roengpitya et al. (2014)'s retail-funded model is the largest deposit driven model ( $66.7 \%$ of total assets), characterised by very high stable funding and quite diversified assets side.

21 The total number of institutions considered in the model for risk assessment is 8526 . Institutions that have been always in the same peer group in the interval 2005-2007 are: 2355 (Group A), $2053(B)$ and $1460(C)$.

22 The remaining 62 distress events are associated with institutions switching peer groups, for example 14 institutions in group $D$ in 2005-2006 moving to group $B$ in 2007; or similarly 11 institutions in group $E$ migrating to group $A$ and so on, with some mixed results in terms of relative sizes.
} 
Table 7 Distribution of distress events for business strategy membership Column names refer to business strategy peer groups in year 2007; row names in bold stand for peer groups in year 2006; finally, row names in italics refer to peer groups in 2005. Source: Authors' own elaborations

\begin{tabular}{|c|c|c|c|c|}
\hline$\downarrow 2006 \backslash 2007 \rightarrow$ & $\mathbf{A}$ & B & $\mathrm{C}$ & $\begin{array}{l}\text { Total (2006) } \\
\text { Sub-total (2005) }\end{array}$ \\
\hline $\mathbf{A}(2005 \downarrow)$ & 67 & 6 & 2 & 75 \\
\hline$A$ & 64 & 4 & 2 & 70 \\
\hline$B$ & 1 & 1 & 0 & 2 \\
\hline C & 1 & 0 & 0 & 1 \\
\hline$D$ & 1 & 0 & 0 & 1 \\
\hline E & 0 & 1 & 0 & 1 \\
\hline B $(2005 \downarrow)$ & 4 & 31 & 0 & 35 \\
\hline$A$ & 1 & 1 & 0 & 2 \\
\hline$B$ & 3 & 28 & 0 & 31 \\
\hline C & 0 & 0 & 0 & 0 \\
\hline$D$ & 0 & 2 & 0 & 2 \\
\hline E & 0 & 0 & 0 & 0 \\
\hline $\mathrm{C}(2005 \downarrow)$ & 1 & 0 & 51 & 52 \\
\hline A & 0 & 0 & 1 & 1 \\
\hline$B$ & 0 & 0 & 0 & 0 \\
\hline C & 1 & 0 & 50 & 51 \\
\hline$D$ & 0 & 0 & 0 & 0 \\
\hline E & 0 & 0 & 0 & 0 \\
\hline D $(2005 \downarrow)$ & 9 & 17 & 4 & 30 \\
\hline A & 2 & 3 & 0 & 5 \\
\hline$B$ & 0 & 0 & 0 & 0 \\
\hline C & 1 & 0 & 0 & 1 \\
\hline$D$ & 6 & 14 & 4 & 24 \\
\hline E & 0 & 0 & 0 & 0 \\
\hline $\mathbf{E}(2005 \downarrow)$ & 11 & 1 & 0 & 12 \\
\hline$A$ & 0 & 0 & 0 & 0 \\
\hline$B$ & 0 & 0 & 0 & 0 \\
\hline C & 0 & 0 & 0 & 0 \\
\hline$D$ & 0 & 0 & 0 & 0 \\
\hline$E$ & 11 & 1 & 0 & 12 \\
\hline Total (2007) & 92 & 55 & 57 & 204 \\
\hline
\end{tabular}

Each cell represents the number of distressed institutions referring to the corresponding combination of peer groups membership. Row Total (2007) shows the number of distressed institutions partitioned according to the three peer groups in 2007; similarly, column Total (2006) stands for the total number of distressed institutions based on classification in 2006. By Sub-Total (2005) we indicate the number of distressed institutions for peer groups in 2005 within partitions of 2006

coverage of $\$ 2 \operatorname{tn}$ in $2007,1 / 5$ of the whole amount of the group with average sizes up to 15 times those of their peer group members.

In contrast, for group $C$ the average size of distressed institutions during the period 20082010 is in line with their peers, with not consistent patterns to be spotted at the country level 
either. For the 50 distress institutions found for group C in 2005-2007, total assets were "just" $\$ 600$ bn compared to the $\$ 24.5 \mathrm{tn}$ of the whole group in 2007, with average sizes even below the average of their peers $(\$ 12.2 \mathrm{bn}$ for the distressed institutions compared with the group average of $\$ 16.8 \mathrm{bn}$ in 2007). This would suggest that relative size on a business strategy with very high stable funding does not matter for purposes of risk assessment. This effect is empirically tested in Sect. 5.

\section{Empirical results on the determinants of banks' distress}

\subsection{Baseline model results (all banks)}

Table 8 reports the results from our baseline models to assess the likelihood of distress during the global financial crisis. The first three specifications regress our dependent variable, i.e. banks' distress events, on each group of predictors separately, i.e. the proxies for CAMELS, the macro and the sectoral dimensions. ${ }^{23}$ The last two columns provide, respectively, the results for: the model that includes all variables and selected variables only. Focusing on the first set of results (column CAMELS) our evidence reveals that in most cases relationships with banks' distress are as expected, with negative and significant effects with the variables Capital, ${ }^{24}$ Cost to Income Ratio, Net Interest margins and our two Liquidity proxies; and positive and significant associations with ROE and Total Securities to Total Assets.

The impact of bank capital is mixed, as more equity over assets seems to be associated with lower risk-taking, as found in similar models proposed by, e.g., Betz et al. (2014) and Vazquez and Federico (2015). However, when considered together with subordinated debts in order to mimic the regulatory capital (the Capital Funding Ratio variable), the sign is positive, although the level of significance is low. There are various possible reasons for this mixed result, including potential moral hazard effects at play at high regulatory capital levels. A caveat of this interpretation might be based on the presence of either non-linear or thresholds effects (Estrella et al. 2000); the model may also suffer from some multicollinearity issue which motivates a more parsimonious model that will be described below.

$\mathrm{ROE}$ is a measure of profitability that may be due to higher risk taking, for example if the denominator is low, so riskier activities seem to have implied higher probability of distress. We anticipate that ROE could ultimately have a negative impact on distress depending on the banks' strategies, a result which would support our intuition on the main hypotheses to discriminate risk drivers among peer groups (see Sect. 5.2).

Large liquid positions influenced negatively the risk of distress, as higher levels of liquidity can strengthen the solvency of the institution (see e.g., Khan et al. 2016). Banks usually follow assets and liabilities management (i.e., ALM) procedures to gauge liquidity, interest rates and currency mismatches of their exposures and to assess the buoyancy of funding and liquidity sources (DeYoung and Jang 2016). Failure to properly manage these sensitivities before the outbreak of financial markets could have undermined the quality of balance sheets and made banks more prone to distress.

The share of securities to total assets (Total security to Total Assets) resembles the sensitivity to market risk. The relationship with the probability of distress can be ambiguous

23 As reported by Cole and White (2012), DeYoung and Torna (2013) and Jin et al. (2011), among others, balance sheet indicators have been successfully included in the assessment of banks' probability of distress together with macro and sectoral controls to improve predictive information.

24 For a deep review on the topic see Shleifer and Vishny (2011). 
Table 8 Distress assessment The first three models refer to specifications within the corresponding group of predictors: CAMELS, Macro and Sector, respectively

\begin{tabular}{|c|c|c|c|c|c|}
\hline & Camels & Macro & Sector & All & Selected \\
\hline Intercept & $\begin{array}{l}-0.740 \\
(0.459)\end{array}$ & $\begin{array}{l}-2.661^{* * *} \\
(0.331)\end{array}$ & $\begin{array}{l}-2.462 \\
(1.710)\end{array}$ & $\begin{array}{l}4.005 \\
(4.420)\end{array}$ & $\begin{array}{l}-0.632 \\
(0.473)\end{array}$ \\
\hline${ }^{C}$ Capital & $\begin{array}{l}-0.048^{* *} \\
(0.023)\end{array}$ & & & $\begin{array}{l}0.024 \\
(0.021)\end{array}$ & $\begin{array}{l}-0.010 \\
(0.013)\end{array}$ \\
\hline${ }^{C}$ Capital funding ratio & $\begin{array}{l}0.036^{*} \\
(0.019)\end{array}$ & & & $\begin{array}{l}-0.038^{* *} \\
(0.017)\end{array}$ & \\
\hline${ }^{A} \mathrm{ROA}$ & $\begin{array}{l}-0.017 \\
(0.074)\end{array}$ & & & $\begin{array}{l}-0.306^{* * *} \\
(0.110)\end{array}$ & $\begin{array}{l}-0.217^{* *} \\
(0.098)\end{array}$ \\
\hline${ }^{M}$ Cost to income ratio & $\begin{array}{l}-0.015^{* * *} \\
(0.005)\end{array}$ & & & $\begin{array}{l}-0.009^{*} \\
(0.006)\end{array}$ & \\
\hline${ }^{M} \mathrm{ROE}$ & $\begin{array}{l}0.023^{* * *} \\
(0.008)\end{array}$ & & & $\begin{array}{l}0.031^{* *} \\
(0.014)\end{array}$ & $\begin{array}{l}0.035^{* * *} \\
(0.010)\end{array}$ \\
\hline${ }^{E}$ Net interest margin & $\begin{array}{l}-0.047^{*} \\
(0.026)\end{array}$ & & & $\begin{array}{l}0.020^{* *} \\
(0.009)\end{array}$ & $\begin{array}{l}-0.070 \\
(0.052)\end{array}$ \\
\hline $\begin{array}{l}E_{\text {Interest expenses to }} \\
\text { Total liabilities }\end{array}$ & $\begin{array}{l}0.026 \\
(0.017)\end{array}$ & & & $\begin{array}{l}0.086^{* * *} \\
(0.031)\end{array}$ & \\
\hline $\begin{array}{l}{ }^{L} \text { Liquid assets to short } \\
\text { Term funding }\end{array}$ & $\begin{array}{l}-0.004^{* *} \\
(0.002)\end{array}$ & & & $\begin{array}{l}-0.001 \\
(0.002)\end{array}$ & \\
\hline $\begin{array}{l}{ }^{L} \text { Deposits to Total } \\
\text { Funding }\end{array}$ & $\begin{array}{l}-0.026^{* * *} \\
(0.004)\end{array}$ & & & $\begin{array}{l}-0.022^{* * *} \\
(0.005)\end{array}$ & $\begin{array}{l}-0.022^{* * *} \\
(0.004)\end{array}$ \\
\hline $\begin{array}{l}S_{\text {Total securities to }} \\
\text { Total assets }\end{array}$ & $\begin{array}{l}0.010^{* *} \\
(0.005)\end{array}$ & & & $\begin{array}{l}0.006 \\
(0.005)\end{array}$ & $\begin{array}{l}0.004 \\
(0.005)\end{array}$ \\
\hline GDP per capita & & $\begin{array}{l}-1.062^{* * *} \\
(0.129)\end{array}$ & & $\begin{array}{l}-0.223 \\
(0.579)\end{array}$ & $\begin{array}{l}-0.605^{* * *} \\
(0.215)\end{array}$ \\
\hline Inflation & & $\begin{array}{l}0.560^{* * *} \\
(0.083)\end{array}$ & & $\begin{array}{l}0.170 \\
(0.362)\end{array}$ & $\begin{array}{l}0.415^{* * *} \\
(0.080)\end{array}$ \\
\hline House price & & $\begin{array}{l}0.085^{* * *} \\
(0.022)\end{array}$ & & $\begin{array}{l}0.220^{* * *} \\
(0.069)\end{array}$ & \\
\hline Unemployment & & $\begin{array}{l}-0.144^{* * *} \\
(0.049)\end{array}$ & & $\begin{array}{l}0.340^{* *} \\
(0.151)\end{array}$ & $\begin{array}{l}0.078^{*} \\
(0.041)\end{array}$ \\
\hline FDI-inflows & & $\begin{array}{l}-0.017 \\
(0.028)\end{array}$ & & $\begin{array}{l}0.142 \\
(0.142)\end{array}$ & \\
\hline FDI-outflows & & $\begin{array}{l}0.088^{* * *} \\
(0.026)\end{array}$ & & $\begin{array}{l}-0.058 \\
(0.187)\end{array}$ & \\
\hline Central Gvt. debt & & & $\begin{array}{l}-0.010^{*} \\
(0.006)\end{array}$ & $\begin{array}{l}-0.015 \\
(0.024)\end{array}$ & \\
\hline
\end{tabular}


Table 8 continued

\begin{tabular}{|c|c|c|c|c|c|}
\hline & Camels & Macro & Sector & All & Selected \\
\hline Gvt. Long-term yield & & & $\begin{array}{l}0.399^{* *} \\
(0.166)\end{array}$ & $\begin{array}{l}-0.795 \\
(0.796)\end{array}$ & \\
\hline $\begin{array}{c}\text { Banks NPLs to } \\
\text { Gross loans }\end{array}$ & & & $\begin{array}{l}-0.201^{* *} \\
(0.091)\end{array}$ & $\begin{array}{l}-0.332^{* * *} \\
(0.125)\end{array}$ & $\begin{array}{l}-0.400^{* * *} \\
(0.080)\end{array}$ \\
\hline $\begin{array}{l}\text { Credit to Non-fin } \\
\text { Sector }\end{array}$ & & & $\begin{array}{l}0.003 \\
(0.008)\end{array}$ & $\begin{array}{l}-0.018^{*} \\
(0.010)\end{array}$ & \\
\hline Market index & & & $\begin{array}{l}-0.129^{* * *} \\
(0.021)\end{array}$ & $\begin{array}{l}-0.133 \\
(0.102)\end{array}$ & $\begin{array}{l}-0.073^{* * *} \\
(0.019)\end{array}$ \\
\hline Sector index & & & $\begin{array}{l}0.023 \\
(0.018)\end{array}$ & $\begin{array}{l}-0.032 \\
(0.091)\end{array}$ & $\begin{array}{l}0.026^{* *} \\
(0.012)\end{array}$ \\
\hline Stock traded & & & $\begin{array}{l}-0.004^{* *} \\
(0.002)\end{array}$ & $\begin{array}{l}0.003 \\
(0.003)\end{array}$ & \\
\hline Num. obs. & 7515 & 7251 & 6243 & 5292 & 6584 \\
\hline Num. distress events & 170 & 179 & 153 & 120 & 137 \\
\hline McFadden's Pseudo $\mathrm{R}^{2}$ & 0.042 & 0.083 & 0.069 & 0.242 & 0.119 \\
\hline McFadden's Adj. Pseudo $\mathrm{R}^{2}$ & 0.027 & 0.073 & 0.056 & 0.188 & 0.097 \\
\hline
\end{tabular}

Column All stands for the model with the entire set of predictors. Column Selected represents a parsimonious model where we include about half of the predictors according mainly to data availability and significance of the coefficients in the single specifications of the model. For variables definitions see Sect. 3. Superscripts $C$, $A, M, E, L, S$ indicate the respective CAMELS dimensions ${ }^{* * *} p<0.01,{ }^{* *} p<0.05,{ }^{*} p<0.1$

since securities represent a volatile source of income, although at the same time these assets can be more liquid than, for example, loans. This aspect was particularly relevant during the recent crisis since the effects of fire-sales made some institutions more vulnerable. Our baseline models point to a marginal and positive effect, although not always statistically significant.

We stress here the importance of macro and sectoral indicators in the prediction of banks' distress. Higher GDP per capita reduced the likelihood of being in distress, so better economic conditions seem to have fostered financial system resilience, whereas higher Inflation and FDI Outflows increased the likelihood of institution's distress (Ostry et al. 2012). We note that the variable House Price had a positive and significant sign which probably outlines the role of the mortgage market whose collapse during the recent crisis heavily influenced financial stability (Cole and White 2012). Odd sign of Unemployment in the Macro model disappears once we introduce a more comprehensive list of predictors. Expected results arise when considering the sectoral analysis, with Market Index returns working in the same direction as GDP per capita, coherently with the high level of correlation among these variables as reported in Table 10 of Appendix B. Marginal negative effects appear for the Central Government Debt and even for the proportion of domestic financial sector NPLs to total loans (Banks NPLs to Gross Loan). Opposite contribution to institutions' resilience was associated with sovereign debt yields (Gvt. Long-Term Yield) whose dynamics usually reflects the country risk appetite by investors. The presence of sovereign instruments in banks' balance sheets often relates to regulatory requirements and the need to fulfill capital constraints based on 
the amount of risk-weighted assets. ${ }^{25}$ Financial institutions are, in fact, usually exposed to sovereign debt instruments, especially domestic issuances, which influence banking practices and impact on the likelihood of being vulnerable to distress from shocks arising in the sovereign debt markets (see e.g., Laeven and Valencia 2012). Macro-economic and sectoral conditions thus play a role in predicting the likelihood of banks' distress, supporting the inclusion of macro-prudential policies as complement to micro-prudential and bank level tools.

For completeness, we also run a specification with all predictors, even though we note that the large number of variables compared with the amount of observations and distress events does not allow for an accurate and proper econometric investigation. The fifth specification aims at circumscribing this issue by implementing a parsimonious model using half of the predictors. The selection of these variables is driven mainly by their coverage within the sample and the significance of the estimates within the single models, but still preserving the representation of all CAMELS dimensions as well as macro and sectoral control variables. Among the individual predictors in this enriched framework we notice that higher levels for both ROA and Deposits to Total Funding facilitated the resilience of the institutions; an opposite contribution emerges for ROE suggesting that increasing propensity to risk taking prior to the crisis predicted institutions to be in distress. At the macro level, we confirm the impact of the country business cycle approximated by the GDP per capita, while high Inflation and Unemployment levels deteriorated banks' stability conditions. At the sectoral level, Market Index has the same negative sign as GDP per capita as presented above. The sectoral market index (Sector Index, i.e. market returns of the financial sector), however, was positively and significantly related to distress, capturing the effect of the financial sector bubble prior to the crisis. It is worth noting that the pseudo $R^{2}$ of the single model regressions are low, while we reach higher values of explained variability in bank probability of distress with the inclusion of a more comprehensive list of predictors (see model Selected). Due to the level of correlations of ROA, ROE and Capital reported in Table 10, Appendix F validates our estimations by providing more in-depth variants of the Selected model. Specifically, we estimate the model by retaining only one of the aforementioned regressors. We also include interaction effects to capture potential effects beyond a simple linear relationship. Results are reported in Table 15.

\subsection{Risk drivers by banks' peer groups}

The information about banks' business strategies represents a valuable opportunity for regulators to investigate institutions' characteristics and vulnerability to distress during the crisis. This would support targeted intervention and more accurate risk monitoring. In this Section we analyze each peer group separately by partitioning the sample according to their 'stable' membership over the interval 2005-2007. This setup allows us to disentangle the impact of being in a particular peer group in the pursuit of testing our main hypothesis. Hence, Table 9 focuses on a restricted case where we discard institutions that switched peer groups prior to the crisis and, therefore, are less representative for those business strategies. Since the number of observations and, in particular, distress events under each peer group is modest, we need to consider a Penalized-likelihood logistic regression with very few predictors. For this analysis we focus on the two core and polar groups $A$ (modern banking) and $C$ (traditional

25 For instance prior to the crisis banks under Basel regulations usually benefit from lower risk-weights for positions on government bonds instead of loans. For details see e.g., BCBS (2013). 
model). ${ }^{26}$ We propose a simple framework with common CAMELS variables and two basic macro predictors (GDP per capita and Inflation) along with two sectoral variables which capture market dynamics (Government LT Yield and Market Index return). Estimates (both the signs and the magnitudes) for the entire set of no-switching institutions (All model) are similar to those discussed in the Selected model of Table 8, providing reassurance against potential endogeneity problems. This also supports the selection of these predictors for the reference model used to create specifications for each peer group. Note that although confined to specific peer groups membership, these configurations share the same setup of previous models to enhance comparability. In addition, we add the level of institutions' total assets as predictor. As discussed in Sect. 4.3, size relative to their peers seems to matter for the event of distress during the recent financial crisis at least for the wholesale-oriented institutions.

Table 9 confirms that dominant assets size relative to their peer group members exacerbated the likelihood of distress only on group $A$, i.e. the most wholesale-oriented model, whereas it had no significant impact for the deposit-oriented group. This finding provides an alternative view on the "too-big-to-fail" problem that can be tailored to specific peer groups. Estimates indicate that groups $A$ and $C$ present quite different risk drivers in terms of CAMELS variables during the global financial crisis: ROE impacted positively on the likelihood of distress for group $A$ institutions and negatively for $C$ ones (although the coefficient magnitude is relatively small), while ROA exhibited an opposite pattern and Capital had a negative sign for group $C$ institutions but did not show significant effects for those in group $A$. The only exception is on the proxy for liquidity that was negative and consistent across model specifications. This result provides supporting evidence on the debates that stress the impact of liquidity to the recent financial crisis (Tirole 2011) as independent of the adopted business strategy.

On the impact of Capital (and reciprocally on leverage), we recall that group $C$ institutions were on average less capitalized (highly leveraged) compared to those in group $A$, and would have definitely benefited from a boost of capital to enhance stability (Berger and Bouwman 2013; Vazquez and Federico 2015). However, we would take a step further into the assessment of leverage via ROA and ROE. Advancing on the explanation on the effect of ROA, we compare the level of diversification on the assets side between traditional deposit-oriented and modern wholesale-oriented groups, more precisely the differences between a loan-focused versus a well diversified investment strategy. Institutions within the highly leveraged business strategy as those in group $C$ could not fully exploit a wide spectrum of investment choices to boost their returns on assets (see Chiorazzo et al. 2008 for evidence in the EU). This was due to a limited range of instruments in their assets side (recall their investment strategy mainly focused on commercial/corporate loans), which probably impacted on their ability to select risk-adjusted profitable investments compared with group $A$ institutions. Empirical evidence shows that deposit funded banks tended to extend more credit lines to firms on longer maturities (Paligorova and Santos 2016) due to their stable funding (Ivashina and Scharfstein 2010; Kashyap et al. 2002), which although promoting profitability would have exposed them to the corporate credit market that was affected by the sub-prime mortgage crisis.

\footnotetext{
26 We omit model specifications for groups $B, D$ and $E$ only due to the limitation of distress events. In Appendix $\mathrm{F}$ we report an alternative specification of the regression models presented in Table 9 where we use proxies to fill missing values, thus enlarging the sample size. Results still show very similar effects. To enhance comparability, the robustness checks in Appendix F also consider the other peer groups omitted in Table 9.
} 
Table 9 Distress assessment within business strategies Columns Group A and Group C refer to observations for institutions that do not change peer group and that belong to that specific business strategy indicated in the name of the column

\begin{tabular}{|c|c|c|c|c|c|}
\hline & All & Group A & Group C & WS oriented & WS oriented (restricted) \\
\hline Intercept & $\begin{array}{l}-2.282^{* * *} \\
(0.537)\end{array}$ & $\begin{array}{l}-1.130 \\
(1.108)\end{array}$ & $\begin{array}{l}4.942^{* * *} \\
(1.764)\end{array}$ & $\begin{array}{l}-2.564^{* * *} \\
(0.628)\end{array}$ & $\begin{array}{l}-1.815^{* *} \\
(0.925)\end{array}$ \\
\hline${ }^{C}$ Capital & $\begin{array}{l}-0.005 \\
(0.015)\end{array}$ & $\begin{array}{l}0.010 \\
(0.013)\end{array}$ & $\begin{array}{l}-0.138^{* *} \\
(0.055)\end{array}$ & $\begin{array}{l}0.006 \\
(0.013)\end{array}$ & $\begin{array}{l}0.018 \\
(0.012)\end{array}$ \\
\hline${ }^{A} \mathrm{ROA}$ & $\begin{array}{l}-0.092 \\
(0.103)\end{array}$ & $\begin{array}{l}-0.175^{*} \\
(0.094)\end{array}$ & $\begin{array}{l}0.678^{* *} \\
(0.286)\end{array}$ & $\begin{array}{l}-0.240^{* *} \\
(0.104)\end{array}$ & $\begin{array}{l}-0.252^{* *} \\
(0.105)\end{array}$ \\
\hline${ }^{M} \mathrm{ROE}$ & $\begin{array}{l}0.025^{* * *} \\
(0.009)\end{array}$ & $\begin{array}{l}0.044^{* * *} \\
(0.015)\end{array}$ & $\begin{array}{l}-0.042^{* *} \\
(0.018)\end{array}$ & $\begin{array}{l}0.038^{* * *} \\
(0.011)\end{array}$ & $\begin{array}{l}0.061^{* * *} \\
(0.015)\end{array}$ \\
\hline${ }^{E}$ Net interest margin & $\begin{array}{l}-0.075^{*} \\
(0.040)\end{array}$ & $\begin{array}{l}0.012 \\
(0.009)\end{array}$ & $\begin{array}{l}0.169 \\
(0.166)\end{array}$ & $\begin{array}{l}-0.082^{* *} \\
(0.036)\end{array}$ & $\begin{array}{l}-0.025 \\
(0.049)\end{array}$ \\
\hline${ }^{L}$ Deposits to total funding & $\begin{array}{l}-0.018^{* * *} \\
(0.004)\end{array}$ & $\begin{array}{l}-0.020^{* * *} \\
(0.006)\end{array}$ & $\begin{array}{l}-0.066^{* * *} \\
(0.015)\end{array}$ & $\begin{array}{l}-0.017^{* * *} \\
(0.005)\end{array}$ & $\begin{array}{l}-0.016^{* * *} \\
(0.006)\end{array}$ \\
\hline$S_{\text {Total securities to total assets }}$ & $\begin{array}{l}-0.007 \\
(0.006)\end{array}$ & $\begin{array}{l}0.004 \\
(0.008)\end{array}$ & $\begin{array}{l}-0.003 \\
(0.012)\end{array}$ & $\begin{array}{l}0.003 \\
(0.007)\end{array}$ & $\begin{array}{l}0.004 \\
(0.008)\end{array}$ \\
\hline GDP per capita & $\begin{array}{l}0.012 \\
(0.107)\end{array}$ & $\begin{array}{l}-0.144 \\
(0.206)\end{array}$ & $\begin{array}{l}-3.061^{\text {*** }} \\
(1.048)\end{array}$ & $\begin{array}{l}0.082 \\
(0.100)\end{array}$ & $\begin{array}{l}-0.043 \\
(0.171)\end{array}$ \\
\hline Inflation & $\begin{array}{l}0.196 \\
(0.130)\end{array}$ & $\begin{array}{l}0.203 \\
(0.220)\end{array}$ & $\begin{array}{l}-0.150 \\
(0.486)\end{array}$ & $\begin{array}{l}0.141 \\
(0.135)\end{array}$ & $\begin{array}{l}0.319 \\
(0.196)\end{array}$ \\
\hline Gvt. Long-term yield & $\begin{array}{l}0.248^{*} \\
(0.136)\end{array}$ & $\begin{array}{l}-0.275 \\
(0.287)\end{array}$ & $\begin{array}{l}0.852^{*} \\
(0.483)\end{array}$ & $\begin{array}{l}0.050 \\
(0.170)\end{array}$ & $\begin{array}{l}-0.242 \\
(0.249)\end{array}$ \\
\hline Market index & $\begin{array}{l}-0.085^{* * *} \\
(0.013)\end{array}$ & $\begin{array}{l}-0.021 \\
(0.022)\end{array}$ & $\begin{array}{l}0.088 \\
(0.062)\end{array}$ & $\begin{array}{l}-0.050^{* * *} \\
(0.013)\end{array}$ & $\begin{array}{l}-0.057^{* * *} \\
(0.017)\end{array}$ \\
\hline Total assets & $\begin{array}{l}2.052^{* * * *} \\
(0.342)\end{array}$ & $\begin{array}{l}1.606^{* * *} \\
(0.476)\end{array}$ & $\begin{array}{l}0.029 \\
(1.450)\end{array}$ & $\begin{array}{l}1.984^{* * *} \\
(0.317)\end{array}$ & $\begin{array}{l}1.531^{* * *} \\
(0.395)\end{array}$ \\
\hline Num. obs. & 5780 & 1867 & 1231 & 4870 & 3450 \\
\hline Num. distress events & 126 & 46 & 46 & 92 & 59 \\
\hline McFadden's Pseudo R ${ }^{2}$ & 0.115 & 0.137 & 0.180 & 0.107 & 0.093 \\
\hline McFadden's Adj. Pseudo $\mathrm{R}^{2}$ & 0.093 & 0.067 & 0.111 & 0.077 & 0.048 \\
\hline
\end{tabular}

Column WS-oriented refers in particular to institutions belonging to groups $A, B, D$ and $E$, admitting for transitions across these groups and never being in group $C$ in the period 2005-2007 (in the case of groups $D$ and $E$ the interval that is considered is 2005-2006). Column WS-oriented (Restricted) is circumscribed to groups $A$ and $B$. Column $A l l$ includes all institutions. For regressors definitions see Sect. 3. Superscripts $C$, $A, M, E, L, S$ indicate the respective CAMELS dimensions. Total Assets are in USD Trillion ${ }^{* * *} p<0.01,{ }^{* *} p<0.05,{ }^{*} p<0.1$

On ROE, the opposite effect would be related to the structure of the liabilities side of the institutions. Group $A$ was already characterized by high exposure to profitable and risky assets, and further investment decisions aimed to improve the level of ROE could have worsen the sustainability of their activities (Stiroh 2004) compared with those in group $C$. This effect is in line with the findings of Demirgüc-Kunt and Huizinga (2010) on the nonlinear effect of the growth of non-deposit funding and non-interest income investments 
to the prediction of distress. Group $A$ institutions had higher exposures to interbank debts, and further investments were indeed likely to involve an increase of this type of leverage, which in turn deteriorated the resilience of this peer group and, eventually, exacerbated their risk of distress during the crisis (Vazquez and Federico 2015); Group $C$ institutions on the other end were characterized by more stable funding, namely deposits, so the mix of funding that they used for investment purposes was less prone to suffer from financial market instability (Beltratti and Stultz 2012). The latter phenomenon can imply contagion dynamics that are related to interbank exposures through which contagion may actually propagate (Krause and Giansante 2012; Cont and Minca 2016). It is worth recalling that the dependence on interbank positions was a specific feature of the wholesale-oriented peer groups, while during the recent crisis customer deposits, dominant funding source in deposit-oriented institutions, were not particularly affected by bank runs triggered by the lack of confidence in banks' quality (for discussions see e.g., Gorton 2010). Furthermore, the interconnectivity arisen from interbank exposures might have determined the need to redefine the bilateral positions during the outbreak of financial markets to compensate for the increasing perception of counterpart risk, thus resulting in more volatile balance sheet compositions. This might have also influenced the reallocation of investments on the assets side, due to constraints on funding sources which reciprocally affected fire-sales dynamics (Anand et al. 2013; Georg 2013).

Finally, we add a specification which includes all the wholesale-oriented institutions in the same group (last column is circumscribed to the merge between $A$ and $B$ groups only). Although the main discussion above compares the two extreme peer groups, namely $A$ and $C$, which is in line with the current debates on business models (see Sect. 2), this further analysis helps validating comparisons between wholesale-oriented models and the deposit-oriented model, due to the inclusion in particular of group $B$ institutions. All three specifications of wholesale models proposed are consistent and estimates reinforce the interpretation that modern wholesale-oriented and traditional deposit-oriented institutions presented different predictive drivers for the likelihood of distress during the recent financial crisis. Thus, our results support our main hypothesis by emphasizing different predictive features of institutions' probability of distress under traditional or modern banking models.

\section{Conclusions}

This study investigates the impact of financial institutions business strategies to the prediction of distress during the 2008 financial crisis. Although empirical evidence suggests that wholesale-funded institutions are more prone to distress due to low levels of stable funding, the recent financial crisis exposed the fragility of all business strategies. We therefore focus our analysis on exploiting banks adopting similar business strategies (peer groups) to estimate the likelihood of distress during the recent financial crisis in order to promote banks classifications as a useful assessment procedure for targeted monitoring.

By partitioning the sample according to peer group memberships that were consistent over the period 2005-2007, we confirm that size (in terms of total assets), and therefore the issue of "too-big-to-fail", had a significant predictive impact only among modern wholesale-oriented models. This is not the case within the traditional depositoriented groups, where size did not play any significant role. We also compare modern 
wholesale-oriented versus traditional deposit-oriented institutions noting opposite patterns for CAMELS risk drivers contributions in predicting the risk of distress: (i) a significant and negative sign for capital (positive for leverage) only for the less capitalized (highly leveraged) deposit-oriented group, thus supporting the idea that recapitalization might not improve resilience for those institutions adopting modern and universal banking practices that already presented heavy capital burden on their risky exposures; (ii) a negative impact of ROE for traditional (not well diversified) business models and positive for modern banking models which captured the impact of leverage based on a stable versus an unstable funding structure; (iii) opposite effects for ROA that reflected the impact of the pursuit of higher assets returns on restricted investment portfolios compared to well diversified ones.

This analysis is expected to provide useful recommendations to regulators, particularly in the context of the identification of early warning signals and the prediction of bank distress. For example, the recent Supervisory Review and Evaluation Process (SREP) put in place in Europe directly states peer group analysis as an important pillar for the sustainability of banking sector. By enriching the mainstream banks' peer group classification, we provide evidence of how each model presents peculiar predictive drivers for the likelihood of distress at a global level, where the one-rule-fits-all approach for monitoring and risk assessment could be dramatically misleading compared to a targeted intervention. The exception we find is on the impact of liquidity that appeared exogenous to business strategy, supporting the new adopted Liquidity Coverage Ratio and Net Stable Funding Ratio introduced by Basel III that are meant to tackle this issue (BCBS 2011).

The case study offered by the recent crisis identifies peculiar financial statement items as drivers for the prediction of banking distress. These variables emerge as distinctive features of their business strategies. In line with our findings, future research could address the reasons behind peer groups instability and the role of liquidity that we show to be quite consistent across business strategies. Funding liquidity risk might be deeper analyzed by exploiting the sensitivity of peer groups to liquidity composition and non-performing loans exposures, including earlier years and quarterly releases to improve the estimation procedure. This would require a more parsimonious set of institutions' features to overcome comparability issues. The vulnerability of banks could also be assessed by other indicators well-adopted in literature, such us the distance to default (z-score), SRISK and MES (Acharya et al. 2012, 2017; Brownlees and Engle 2016), $\triangle$ COVAR (Adrian and Brunnermeier 2011), or DIP (Huang et al. 2009), which can be easily included in our framework, as well as more focused macro and sector indicators designed for specific distress events within the geographical versus peer group space.

Acknowledgements The authors are grateful for comments from the guest editors and two anonymous referees that have improved the paper. We also thank inputs from Ozlem Akin, Kim Cuong Ly, Pietro Perotti, Steven Ongena, participants of the Workshop on Bank Business Models at Cass Business School, and seminars at the University of Bath School of Management, University of Reading ICMA centre, IMT Lucca, Polytechnic University of Milan and University of Swansea.

Open Access This article is distributed under the terms of the Creative Commons Attribution 4.0 International License (http://creativecommons.org/licenses/by/4.0/), which permits unrestricted use, distribution, and reproduction in any medium, provided you give appropriate credit to the original author(s) and the source, provide a link to the Creative Commons license, and indicate if changes were made. 


\section{Appendix}

\section{A Description of the aggregated measures}

In the study of peer groups features we employ a set of aggregated measures which synthesise balance sheet items. The selection of these measures helps the interpretation of peer groups in terms of their business strategies because provides a less granular representation of balance sheet dimensions which, otherwise, would have make the multiple pairwise comparisons very complex. In addition, this choice partially overcomes the issues related to the presence of missing values within the set of variables used to compute the cosine similarities. The following measures are chosen among those usually applied in literature to detect banks' peer groups. These aggregates are computed on standardized balance sheet variables, i.e. the constituents of each aggregated dimension are standardized by the total assets of the respective institution.

- Retail Loans = Residential Mortgage Loans + Other Mortgage Loans + Other Consumer/Retail Loans

- Corporate and Other Loans = Corporate and Commercial Loans + Other Loans

- Retail and Corporate Loans = Residential Mortgage Loans + Other Mortgage Loans + Other Consumer/Retail Loans + Corporate and Commercial Loans + Other Loans

- Total Loans = Residential Mortgage Loans + Other Mortgage Loans + Other Consumer/Retail Loans + Corporate and Commercial Loans + Other Loans + Loans and Advances to Banks

- Interbank Lending = Loans and Advances to Banks + Reverse Repos and Cash Collateral

- Investments = At Equity Investments in Associates + Available for Sale Securities + Trading Securities and At FV Through Income + Held to Maturity Securities + Other Securities

- Customer Deposits = Customer Deposits (Current, Savings, Term)

- Interbank Borrowing = Deposits from Banks + Other Deposits and Short-Term Borrowings + Repos and Cash Collateral

- Long-Term Funding = Senior Debt Maturing After 1 Year + Subordinated Borrowing + Other Funding

- Long-Term Funding + Equity = Senior Debt Maturing After 1 Year + Subordinated Borrowing + Other Funding + Total Equity

- Wholesale Debt $=$ Senior Debt Maturing After 1 Year + Subordinated Borrowing + Other Funding + Other Deposits and Short-Term Borrowings + Deposits from Banks

- Stable Funding = Senior Debt Maturing After 1 Year + Subordinated Borrowing + Other Funding + Other Liabilities + Customer Deposits (Current, Savings, Term)

- Stable Funding $-\mathrm{CORE}=$ Senior Debt Maturing After 1 Year + Subordinated Borrowing + Customer Deposits (Current, Savings, Term)

- Net Liquidity = Cash and Due From Banks + Reverse Repos and Cash Collateral Deposits from Banks - Other Deposits and Short-Term Borrowings - Repos and Cash Collateral - Customer Deposits (Current, Savings, Term)

\section{B Correlation matrix}

See Table 10. 


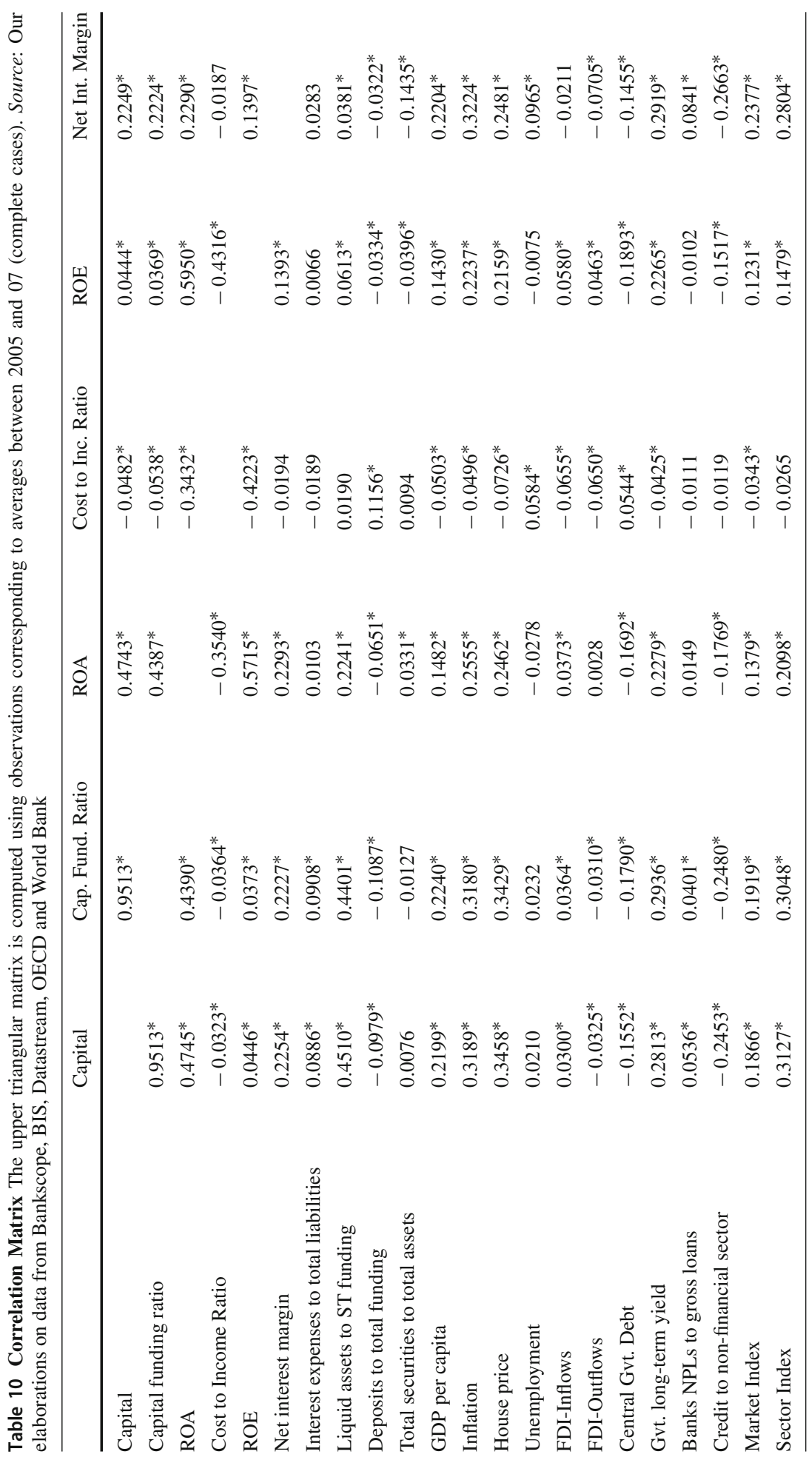




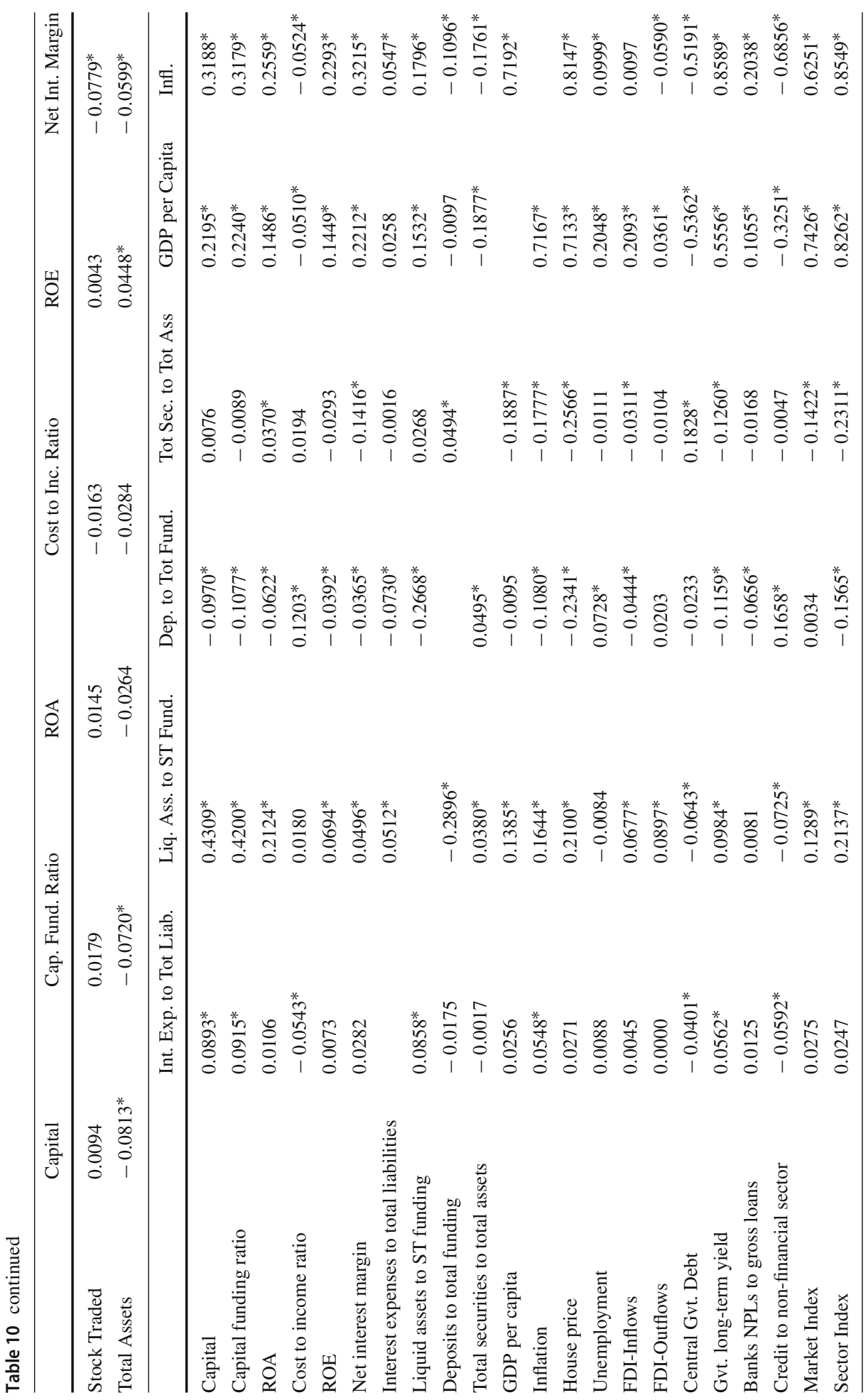




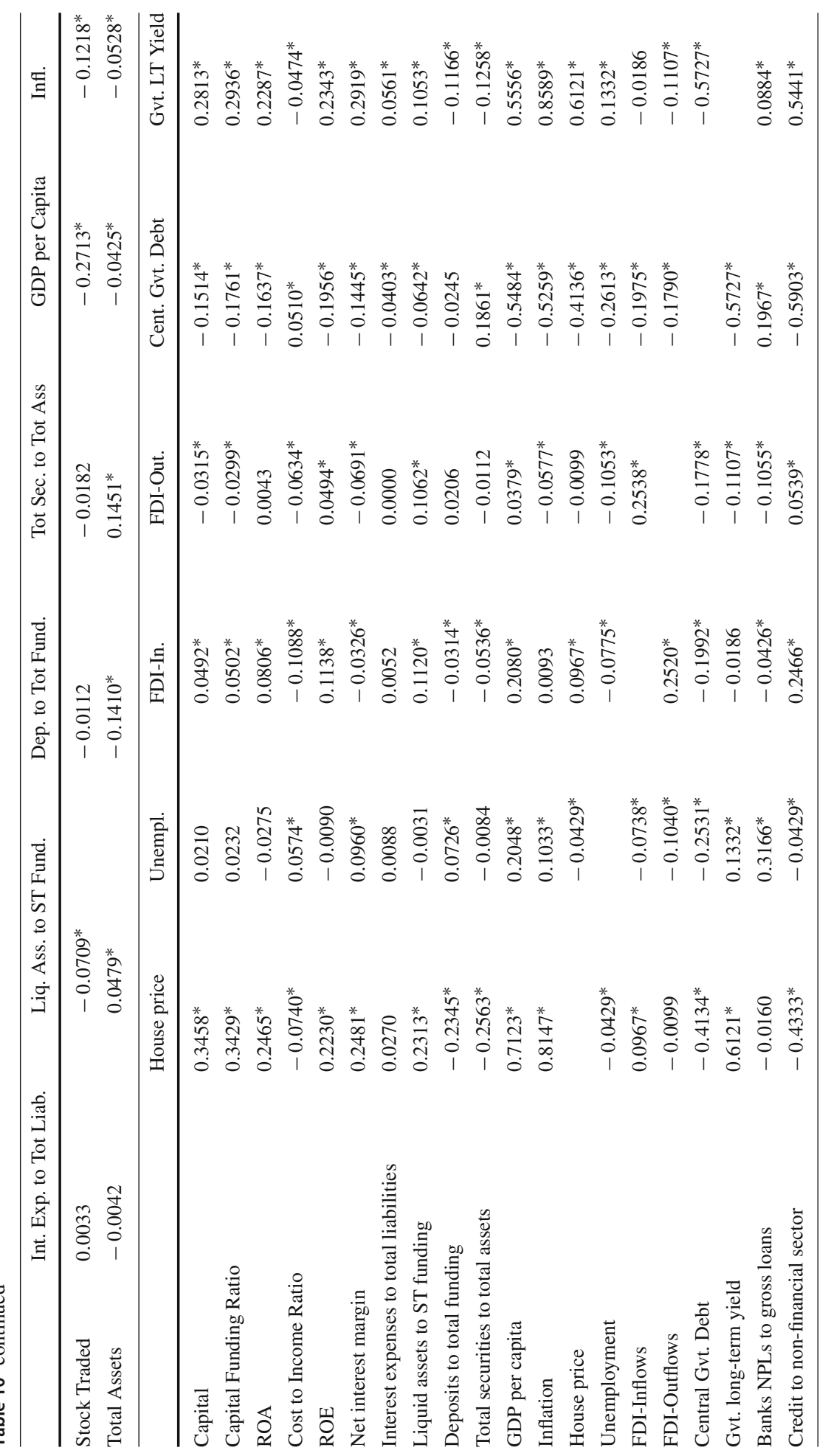




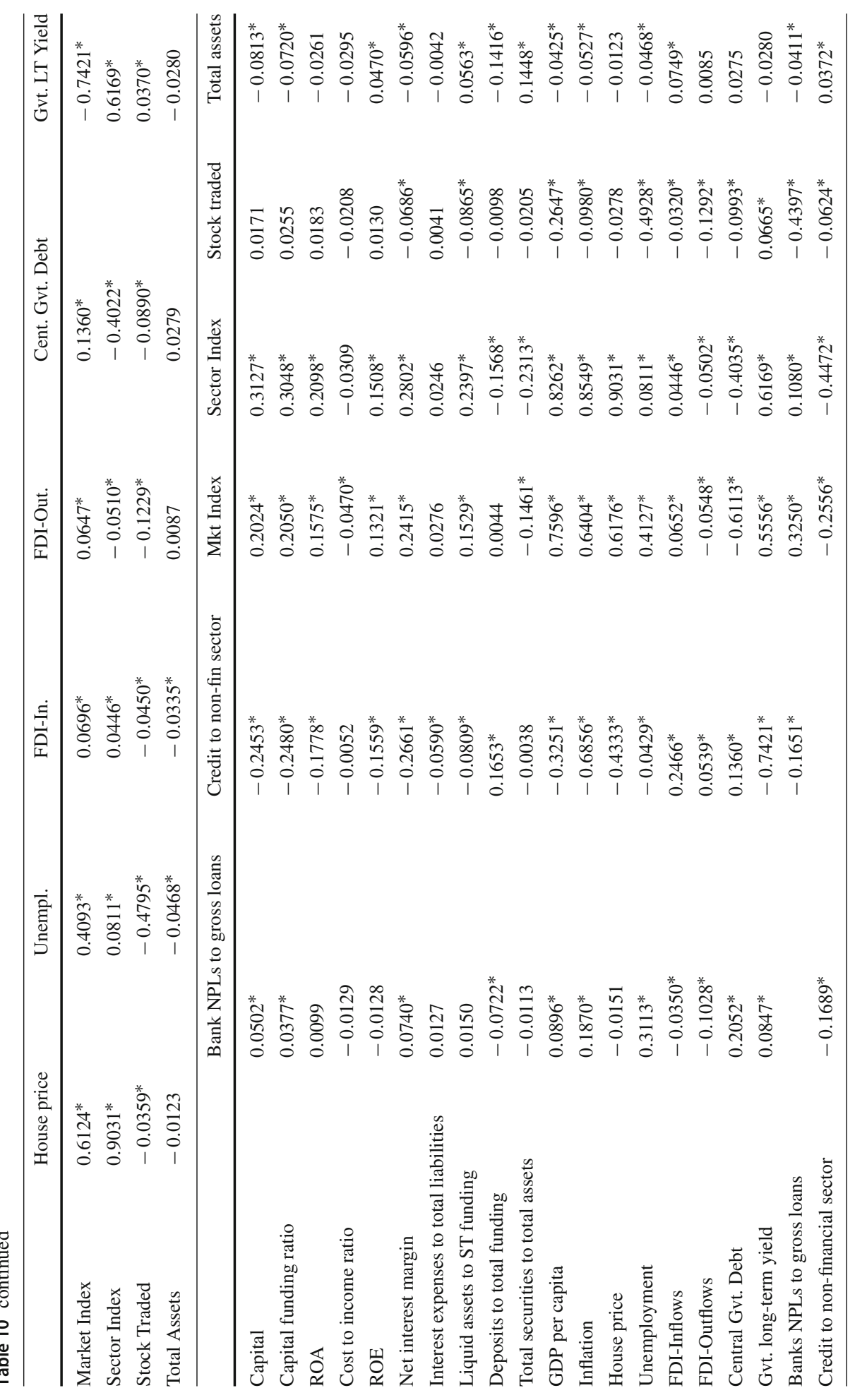




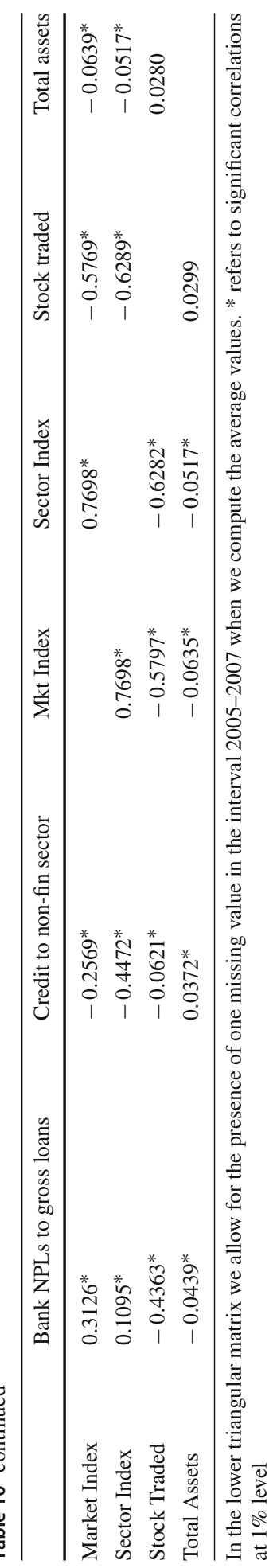

照 Springer 


\section{Classification method}

Given two vectors $x$ and $y$, their cosine similarity ${ }^{27}$ is computed as follows:

$$
\operatorname{Cos} \operatorname{Sim}(x, y)=\frac{\sum_{i} x_{i} y_{i}}{\sqrt{\sum_{i} x_{i}^{2}} \sqrt{\sum_{i} y_{i}^{2}}}=\frac{<x, y>}{\|x\|\|y\|}
$$

Once we have measured the pair-wise similarities among institutions we apply a hierarchical clustering algorithm which identifies groups by maximizing the modularity quantity. This approach is common in complex system literature where the system resembles a graph or network of nodes (i.e., the financial institutions in our case) connected by means of edges (which link pairs of nodes/institutions and are weighted according to the similarities among them). Modularity measures the strength of division of a system into clusters or communities, where these groups of densely interconnected nodes are only sparsely connected with the rest of the system (Newman and Girvan 2004). The modularity is computed as:

$$
Q=\frac{1}{2 m} \sum_{i, j}\left[A_{i j}-\frac{k_{i} k_{j}}{2 m}\right] \delta\left(c_{i}, c_{j}\right)
$$

where $A_{i j}$ indicates the weight of the edge between nodes $i$ and $j$ (i.e., the similarity among this pair of institutions), $k_{i}=\sum_{j} A_{i j}$ represents the sum of the weights of the edges connected to node $i$ (basically it measures the similarity of institution $i$ to the rest of the system), $c_{i}$ is the cluster to which node $i$ belongs (i.e., the peer group), $\delta(u, v)$ is equal to 1 if $u=v$ and 0 otherwise, and $m=\frac{1}{2} \sum_{i, j} A_{i j}$. Among the approaches proposed in literature to optimise this quantity (hence, to provide a better partition of the system in clusters), we apply the Louvain method (Blondel et al. 2008) that has received an increasing interest in complex systems literature. This algorithm is structured in two phases. ${ }^{28}$ Firstly, each institution is assigned to a single cluster (namely, peer group), so there are as many clusters as there are institutions. Hence, for each institution the algorithm considers its neighbourhood and evaluates the gain of modularity that can be obtained by joining a different cluster. The combination of nodes assigned to clusters that gives the maximum gain (if positive) is therefore performed. Then, the same process is repeated for all institutions until no further improvements in modularity are achieved. The gain in modularity (i.e., $\Delta Q$ ) by moving an isolated institution $i$ into a cluster $c$ can be measured as follows:

$$
\Delta Q=\left[\frac{\sum_{i n}+k_{i, i n}}{2 m}-\left(\frac{\sum_{t o t}+k_{i}}{2 m}\right)^{2}\right]-\left[\frac{\sum_{i n}}{2 m}-\left(\frac{\sum_{t o t}}{2 m}\right)^{2}-\left(\frac{k_{i}}{2 m}\right)^{2}\right]
$$

where $\sum_{i n}$ is the sum of the weights of the edges (i.e., the similarities) within the cluster $c$, and $\sum_{t o t}$ is the sum of the weights of the edges attaching to nodes in cluster $c$, while $k_{i}$ is the sum of the weights of the edges received by node $i$ and $k_{i, i n}$ is the sum of the weights of the edges from $i$ to nodes belonged to cluster $c$, and $m$ is the total sum of the weights of all the edges in the system. Therefore, in the second phase the algorithm builds a new hierarchical partition in which nodes are here those clusters identified in the previous step,

27 Each component of the vector can be weighted according to the importance of that variable to the assessment of similarities among pairs of institutions. However, we adopt a neutral approach and we treat all information in the vector with the same importance to avoid ex-ante manipulation for the results.

28 This part refers to the original paper by Blondel et al. (2008). We rely on their formulation for presenting the main characteristics of the algorithm. For a deep review of community detection methodologies, see e.g. Fortunato (2010). 
meaning that it re-applies the same procedure of the first phase to the resulting weighted system of meta-nodes. This approach is iterated until a maximum of modularity is achieved.

Cosine similarities can actually assume positive or negative values (this is due to the fact that balance sheet items may be either positive or negative). The Louvain community detection algorithm requires that edges with higher values are assigned to stronger similarities. Therefore, we first get a distance metrics applying the metric preserving transformation $\theta_{i, j}=\sqrt{0.5\left(1-C S_{i, j}\right)}$, where $\theta_{i, j} \in[0,1]$ and $C S_{i, j}$ is the cosine similarity between $i$ and $j$, which ensures that similarities range between 0 and 1 (van Dongen and Enright 2012). Then, we define the value of pair-wise similarity between $(i, j)$ as $1-\theta_{i, j}$, so that pairs of institutions which are very similar receive higher weights. This approach is in line with Puliga et al. (2016), where a similar clustering strategy is applied to classify a smaller set of banks than ours and to detect the main economic features characterizing the emerging communities and with Flori et al. (2019) where a similar approach is applied to detect distinctive behavioral traits among investment funds.

A few technical issues should be taken into account. First, for each year we prune the system by removing the edges below the 0.025 and above the 99.975 percentiles of the cosine similarity distribution. Second, since the system is very dense by construction, we remove redundant edges avoiding its fragmentation, i.e. keeping the system connected. We test several specifications by filtering edges below certain thresholds. ${ }^{29}$ We recall that edges with higher values stand for higher similarity between pairs of institutions and the goal of the algorithm is to find clusters of similar institutions. We rely on the idea of finding such dense system in an Erdos-Renyi random graph, that is we maximize $H=\sum_{c} M_{c} D\left(p_{c} \| p\right)$, where $M_{c}$ stands for the number of possible edges in the community $c$ (i.e., $n_{c}\left(n_{c}-1\right) / 2$ ), $p_{c}$ is the density of the community $c, p$ is the general density of the graph and $D(x \| y)$ is the binary Kullback-Leibler divergence (see Traag et al. 2013). Finally, among values of $H$ which are candidates for being the maximum, we usually prefer those that present higher values of modularity unless it implies a tight pruning of the edges.

In addition, we provide a further analysis of the emerging clusters by testing the distributions of their constituents. We employ non-parametric equality of medians tests (i.e., Kruskal-Wallis test) to verify whether clusters originate from the same distribution. We consider a wide set of variables and test non-parametrically whether clusters differentiate from each other for each year in the interval from 2005 to 2014. Results indicate the presence of differences in medians which we have further analysed by means of post-hoc multiple pairwise comparisons (i.e., Dunn tests). Test results are available from the authors upon request.

Our choice of the algorithm to detect peer groups reflects the aim to rely on a clustering approach that is in line with previous and established literature on peer group identification. Both the Louvain and the Ward methods are hierarchical clustering algorithms and the quantities they maximize to find clusters are somehow similar (modularity vs. between/within variances). Moreover, the non-parametric Kruskal-Wallis tests to detect differences among clusters and the multiple pairwise post-hoc comparisons, which we use to further verify that groups are distinct, resemble the Pseudo-F Index framework used in Ward to identify the best configuration of clusters.

29 In particular, we filter the system according to thresholds from 0.7 to 0.5 using a decreasing step equals to 0.025 and, for each year, we select the threshold which maximizes the significance of the configuration. 


\section{Geographic distribution of peer groups}

In this Appendix the geographic distribution of business strategy peer groups is presented. Evidence from Fig. 1 confirms a good coverage of all peer groups across major countries. The latter have been selected on the basis of the representation of institutions and geographic regions in our dataset. Note that the two non-core groups $D$ and $E$ were only adopted in the first 2 years of our pre-crisis period. Banks adopting those models migrated to groups $B$ and $A$ respectively in 2007 as reported in Appendix E. In order to provide more sensible average values of the pre-crisis period, Fig. 1 aggregates non-core models with core ones according to the similarity and migration features of 2007.

\section{E Transitions across business strategy peer groups}

In this Appendix we focus on the transitions of financial institutions across peer groups. Knowing that institutions tend to belong to the same peer groups over time, i.e. a very low transition probability, would validate our identification of peer groups.

Figure 2 exhibits that institutions tend to persist in the same peer group during the biennium 2005-2006, while the disappearance of both groups $D$ and $E$ in 2007 determined a migration of these banks into the three core business strategies. Consistently with their funding orientations, institutions belonging to group $D$ and $E$ in 2006 migrated mainly to the other two available wholesale-oriented models, i.e. groups $A$ and $B$. We note that almost all group $E$ institutions (98.2\%) moved to the group $A$, most probably for the assets side diversification that the group $A$ model offers to institutions that used to have $73 \%$ of their assets invested in retail loans (see Table 6). A different dynamics affects institutions in group $D$, which predominantly migrated to group $B$ due to the similarity between their assets structures. Only $16.7 \%$ of group $D$ institutions moved to group $A$ and, as expected, just a few (3.8\%) converted drastically to the deposit-oriented peer group $\mathrm{C}$.

Table 11 provides the membership stability over time, that is the percentage of institutions that were in the same peer group from the previous year. With an average of almost $90 \%$, membership to peer group seems to be quite stable over the period 2005-2014, thus confirming that these business strategies are basically composed by a constant set of institutions during the reference period. This result also validates the effectiveness of our peer group assessment on the inter-temporal dimension. We also notice a breakpoint in correspondence of the collapse of 2007. In this year the three core business strategies, and especially the wholesale-oriented groups, were contaminated by the inflows of institutions from the other two groups. ${ }^{30}$ Wholesale-oriented business strategies are those more affected by the inclusion of institutions belonging to different groups in the biennium prior to the crisis, however percentages shown in Table 11 indicate that still in 2007 these business strategies maintain a high proportion of members that belonged in 2006 to the same peer groups.

Finally, it is worth underlining that stability of peer groups over time in terms of balance sheets characteristics is obviously a high desirable requirement for a reasonable classification approach, although a certain degree of variability might be due to the normal updating process of banking activities. Since this sample period includes one of the most significant event in the sustainability of the financial markets, it seems realistic that institutions reacted differently

30 Although one might argue that the resulting three groups in 2007 and hereinafter are no longer the same as the ones emerged in 2005-2006, we still observe a reasonable continuity in the distributions of balance sheet values around the crisis of 2007. 


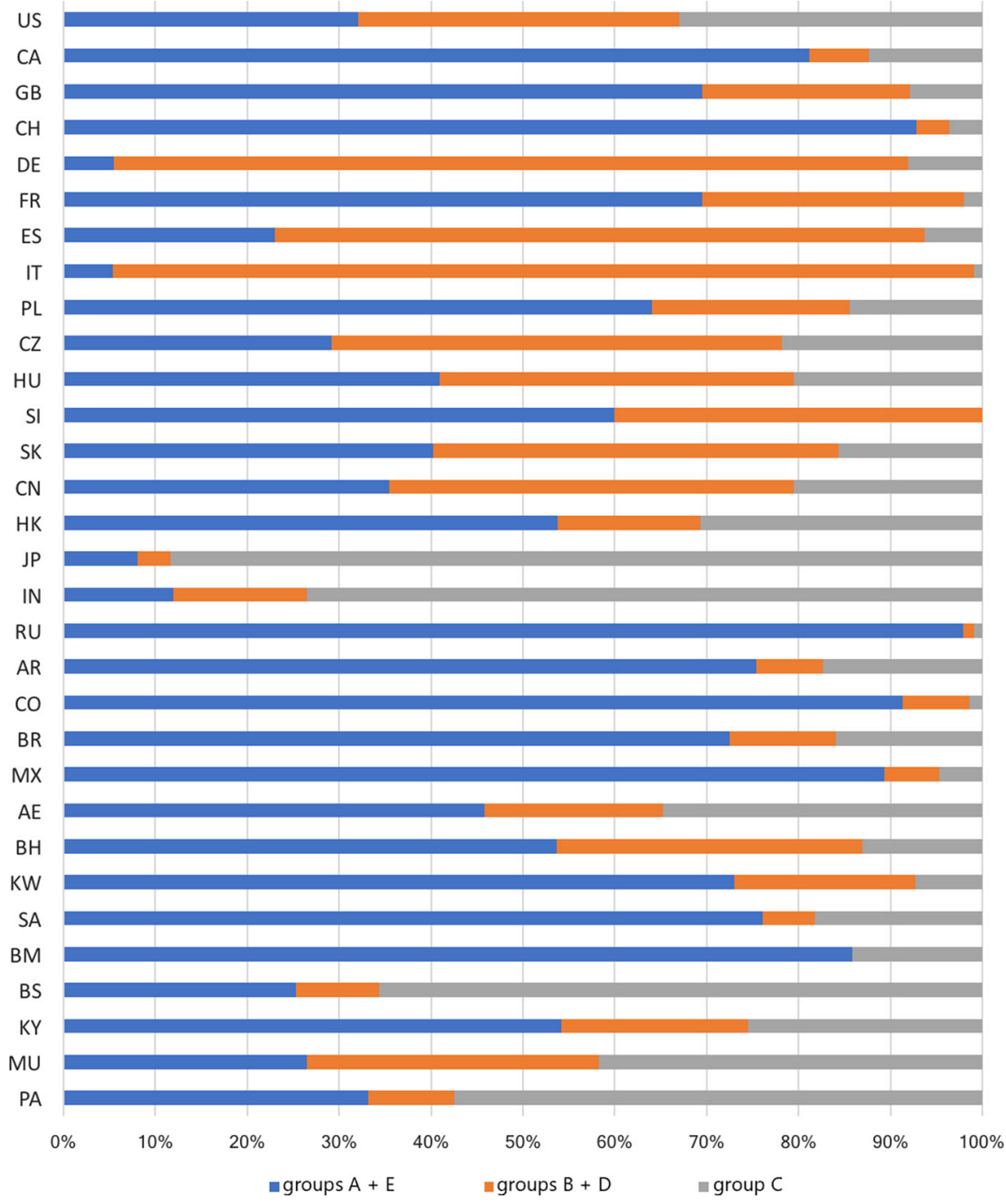

Fig. 1 Geographic coverage of peer groups in the pre-crisis period (average values 2005-2007). The plot shows the representation of banking peer groups within major countries and geographic areas, including Islamic and off-shore financial centers. Percentage values are calculated among all banks classified by our clustering method, averaged across the 3 years 2005-2007. The sample covers more than $90 \%$ of banks' total assets of the country, enhancing the representation of the countries banking system in our analysis. ISO code- 2 is used for countries identifications. Starting from the top we have United States (US), Canada (CA), Great Britain (GB) and Switzerland (CH); for West European countries we have Germany (DE), France (FR), Spain (ES) and Italy (IT); for East Europe Poland (PL), Czech Republic (CZ), Hungary (HU), Slovenia (SI) and Slovakia (SK); for Asia: China (CN), Honk Kong (HK), Japan (JP), India (IN) and Russian Federation (RU); for Latin America: Argentina (AR), Colombia (CO), Brazil (BR) and Mexico (MX); for Islamic countries: United Arab Emirates (AE), Bahrain (BH), Kuwait (KW) and Saudi Arabia (SA); for the off-shores financial centers we have Bermuda (BM), Bahamas (BS), Cayman Islands (KY), Mauritius (MU) and Panama (PA). Source: Bankscope, authors' own elaborations 

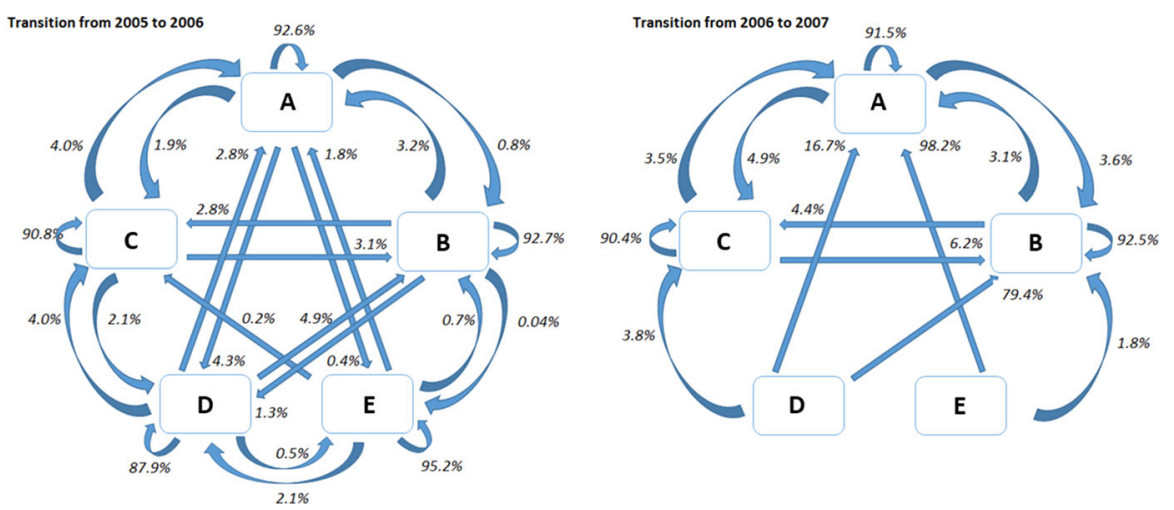

Fig. 2 Business strategy transitions. The plot shows the percentages of institutions belonging to a certain peer group in one period and switching to another group in the next period. Plot on left refers to switches from 2005 to 2006, while plot on the right is for transitions from 2006 to 2007. Source: Authors' own elaborations

from the past against the deteriorated market conditions and that business models have been greatly influenced by the wave of financial turmoil. This, in turn, poses several issues in the recognition of consistent peer groups and in the assessment of the coherence of these groups over time. In particular, before the breakdown of financial market in 2007 institutions experienced a high level of deregulation and financial innovation, while after the onset of the crisis the establishment of a new regulatory framework (e.g., the Basel III regulations and the Dodd-Frank Act) as well as macro and micro prudential decisions pointed to a more robust and regulated financial system. Our results indicate the presence of three main peer groups which persist during the entire interval 2005-2014 and that present quite stable balance sheet figures.

\section{F Robustness checks}

To investigate the risk of distress across different business strategies, we present in Table 12 the same regression models as shown in Table 9 but where (i) we admit the presence of one missing value in the computation of average values for predictors and (ii) we replace missing values for macro and sectoral variables with geographical aggregated proxies. Results are in line with those shown in Table 9, with estimates slightly more significant for macro and sectoral predictors and less for CAMELS.

Although we are aware that a proper econometric analysis for groups $D$ and $E$ should consider a smaller list of predictors, we still estimate the model for these groups to provide comparisons with the $A$ and $C$ core peer groups. We also add group $B$ whose few distress events, mainly concentrated in US, makes the estimation not well defined. For these institutions we also exploit additional data from FDIC to compute the predictors and enlarge the list of distressed institutions. Group $D$ has a negative and significant coefficient for Net Interest Margin, while the coefficient for Total Assets is positive and significant; for group $E$ institutions we observe less consistency with the other wholesale-oriented models and stronger roles for control variables. We remark that due to the small number of observations and the absence of a sufficient set of distressed institutions, results for the last two models should be taken with caution. Furthermore, even in this approximated scenario, estimates are quite 


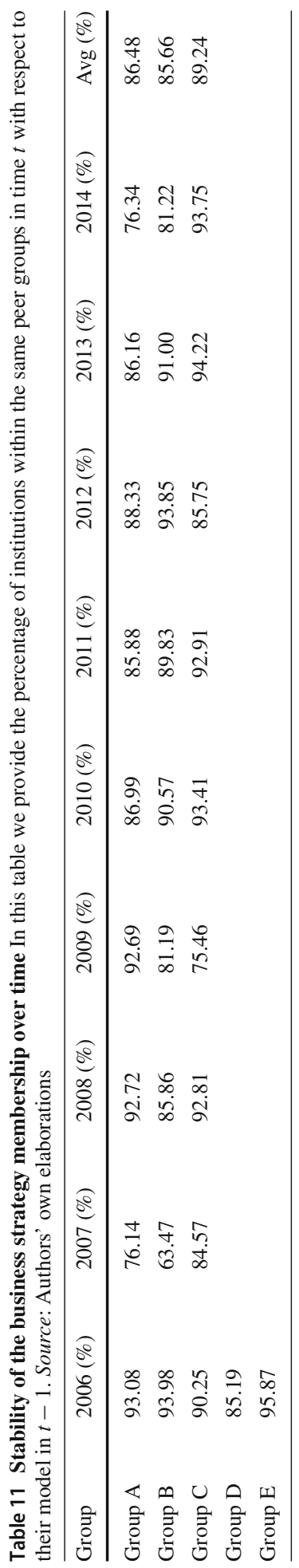




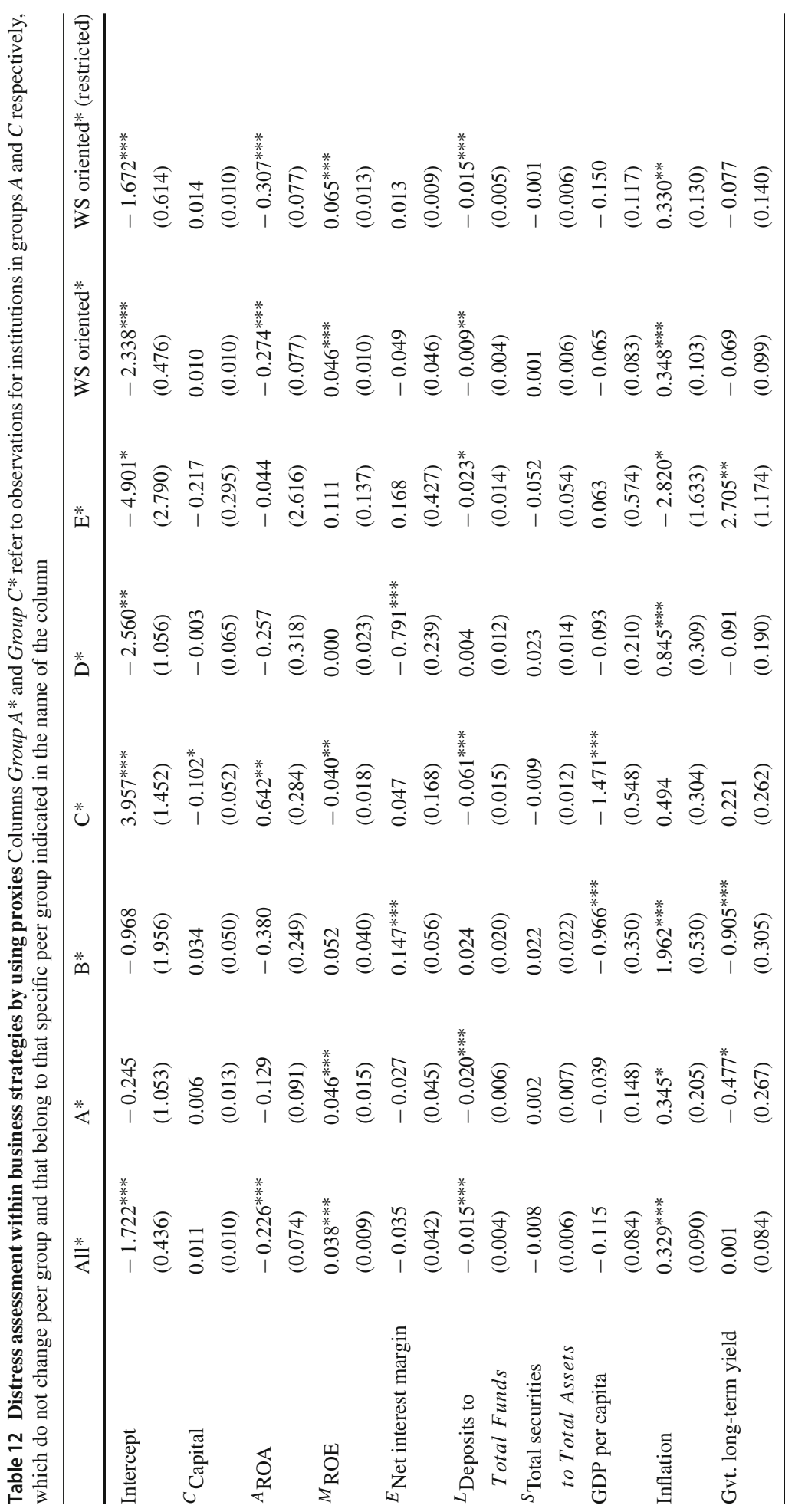




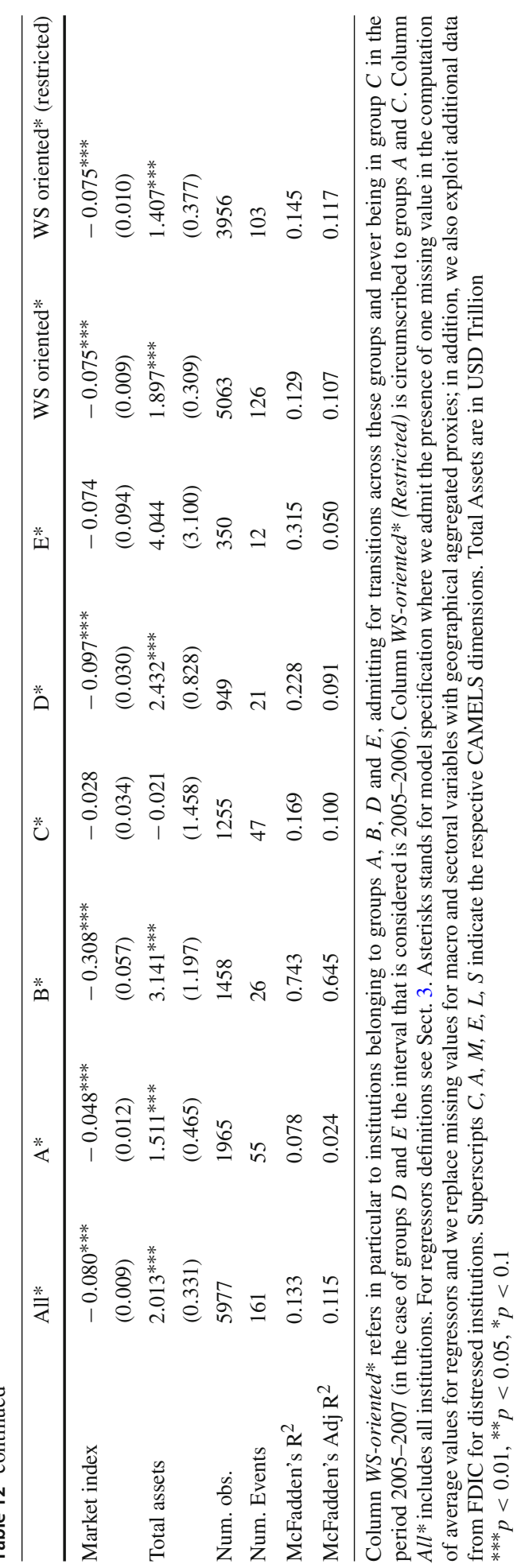


Table 13 Distress assessment: capital adequacy Column (1) refers to the reference model Selected shown in Table 8

\begin{tabular}{|c|c|c|c|}
\hline & \multicolumn{3}{|c|}{ Dependent variable } \\
\hline & $\begin{array}{l}\text { Distress } \\
\text { (1) }\end{array}$ & (2) & (3) \\
\hline Intercept & $\begin{array}{l}-0.632 \\
(0.473)\end{array}$ & $\begin{array}{l}0.071 \\
(0.615)\end{array}$ & $\begin{array}{l}-0.467 \\
(0.549)\end{array}$ \\
\hline${ }^{C}$ Capital & $\begin{array}{l}-0.010 \\
(0.013)\end{array}$ & & \\
\hline${ }^{C}$ Tier 1 & & $\begin{array}{l}-0.002 \\
(0.006)\end{array}$ & \\
\hline${ }^{C}$ Total Capital Ratio & & & $\begin{array}{l}-0.001 \\
(0.003)\end{array}$ \\
\hline${ }^{A} \mathrm{ROA}$ & $\begin{array}{l}-0.217^{* *} \\
(0.098)\end{array}$ & $\begin{array}{l}-0.047 \\
(0.088)\end{array}$ & $\begin{array}{l}-0.234^{*} \\
(0.138)\end{array}$ \\
\hline${ }^{M} \mathrm{ROE}$ & $\begin{array}{l}0.035^{* * *} \\
(0.010)\end{array}$ & $\begin{array}{l}0.012 \\
(0.015)\end{array}$ & $\begin{array}{l}0.022 \\
(0.014)\end{array}$ \\
\hline${ }^{E}$ Net interest margin & $\begin{array}{l}-0.070 \\
(0.052)\end{array}$ & $\begin{array}{l}-0.099 \\
(0.076)\end{array}$ & $\begin{array}{l}-0.065 \\
(0.071)\end{array}$ \\
\hline${ }^{L}$ Deposits to total funding & $\begin{array}{l}-0.022^{* * *} \\
(0.004)\end{array}$ & $\begin{array}{l}-0.034^{* * *} \\
(0.006)\end{array}$ & $\begin{array}{l}-0.030^{* * *} \\
(0.005)\end{array}$ \\
\hline$S_{\text {Total securities to total assets }}$ & $\begin{array}{l}0.004 \\
(0.005)\end{array}$ & $\begin{array}{l}0.004 \\
(0.008)\end{array}$ & $\begin{array}{l}0.006 \\
(0.007)\end{array}$ \\
\hline GDP per Capita & $\begin{array}{l}-0.605^{* * *} \\
(0.215)\end{array}$ & $\begin{array}{l}-0.011 \\
(0.255)\end{array}$ & $\begin{array}{l}0.128 \\
(0.185)\end{array}$ \\
\hline Inflation & $\begin{array}{l}0.415^{* * *} \\
(0.080)\end{array}$ & $\begin{array}{l}0.391^{* * *} \\
(0.124)\end{array}$ & $\begin{array}{l}0.338^{* * *} \\
(0.102)\end{array}$ \\
\hline Unemployment & $\begin{array}{l}0.078^{*} \\
(0.041)\end{array}$ & $\begin{array}{l}0.030 \\
(0.049)\end{array}$ & $\begin{array}{l}0.030 \\
(0.046)\end{array}$ \\
\hline Banks NPLs to gross loans & $\begin{array}{l}-0.400^{* * *} \\
(0.080)\end{array}$ & $\begin{array}{l}-0.415^{\text {*** }} \\
(0.093)\end{array}$ & $\begin{array}{l}-0.387^{* * *} \\
(0.085)\end{array}$ \\
\hline Market index & $\begin{array}{l}-0.073^{* * *} \\
(0.019)\end{array}$ & $\begin{array}{l}-0.069^{* * *} \\
(0.025)\end{array}$ & $\begin{array}{l}-0.076^{* * *} \\
(0.022)\end{array}$ \\
\hline Sector index & $\begin{array}{l}0.026^{* *} \\
(0.012)\end{array}$ & $\begin{array}{l}0.012 \\
(0.015)\end{array}$ & $\begin{array}{l}0.011 \\
(0.012)\end{array}$ \\
\hline Observations & 6584 & 2015 & 2215 \\
\hline Log likelihood & -569.985 & -314.442 & -332.892 \\
\hline Akaike Inf. Crit. & 1165.970 & 654.884 & 691.784 \\
\hline
\end{tabular}

Column (2) is the model in which Capital Adequacy is proxied by the Tier 1 ratio, while in column (3) we consider the Total Capital Ratio

${ }^{*} p<0.1 ;{ }^{* *} p<0.05 ;{ }^{* * *} p<0.01$ 
Table 14 Distress assessment: asset quality Column (1) refers to the reference model Selected shown in Table 8

\section{Dependent variable}

Distress

(1)

Intercept
${ }^{C}$ Capital
${ }^{A} \mathrm{ROA}$
${ }^{A}$ Impaired loans to gross loans
${ }^{A}$ Loan loss reserves to impaired loans

$-0.632$

(0.473)

$-0.010$

(0.013)

(2)

3)

$-0.217^{* *}$

(0.098)

${ }^{M_{\text {ROE }}}$

${ }^{E}$ Net interest margin

${ }^{L}$ Deposits to total funding

$S_{\text {Total securities to total assets }}$

GDP per capita

Inflation

Unemployment

Banks NPLs to gross loans

Market index

Sector index

Observations

Log likelihood

Akaike Inf. Crit.

$-0.255$

(0.575)

0.069

(0.620)

$-0.024$

$-0.080^{* *}$

(0.017)

(0.034)

(0.014)

\begin{tabular}{|c|c|c|}
\hline & & $\begin{array}{l}-0.002^{* *} \\
(0.001)\end{array}$ \\
\hline $0.035^{* * *}$ & 0.014 & 0.014 \\
\hline$(0.010)$ & $(0.010)$ & $(0.010)$ \\
\hline-0.070 & 0.015 & 0.050 \\
\hline$(0.052)$ & $(0.031)$ & $(0.031)$ \\
\hline$-0.022^{* * *}$ & $-0.040^{* * *}$ & $-0.033^{* * *}$ \\
\hline$(0.004)$ & $(0.005)$ & $(0.006)$ \\
\hline 0.004 & $0.016^{* *}$ & $0.016^{*}$ \\
\hline$(0.005)$ & $(0.008)$ & $(0.008)$ \\
\hline$-0.605^{* * *}$ & 0.104 & -0.037 \\
\hline$(0.215)$ & $(0.196)$ & $(0.228)$ \\
\hline $0.415^{* * *}$ & $0.329^{* * *}$ & $0.472^{* * *}$ \\
\hline$(0.080)$ & $(0.086)$ & $(0.097)$ \\
\hline $0.078^{*}$ & $0.081^{*}$ & 0.057 \\
\hline$(0.041)$ & $(0.045)$ & $(0.045)$ \\
\hline$-0.400^{* * *}$ & $-0.323^{* *}$ & $-0.368^{* * *}$ \\
\hline$(0.080)$ & $(0.130)$ & $(0.140)$ \\
\hline$-0.073^{* * *}$ & $-0.061^{* *}$ & $-0.061^{* *}$ \\
\hline$(0.019)$ & $(0.025)$ & $(0.026)$ \\
\hline $0.026^{* *}$ & -0.015 & -0.013 \\
\hline$(0.012)$ & $(0.011)$ & $(0.012)$ \\
\hline 6584 & 2854 & 2454 \\
\hline-569.985 & -335.968 & -288.998 \\
\hline 1165.970 & 697.935 & 603.997 \\
\hline
\end{tabular}

Column (2) is the model in which Asset Quality is proxied by the Impaired Loans to Gross Loans, while in column (3) we consider the Loan Loss Reserves to Impaired Loans

${ }^{*} p<0.1 ;{ }^{* *} p<0.05 ;{ }^{* * *} p<0.01$ 


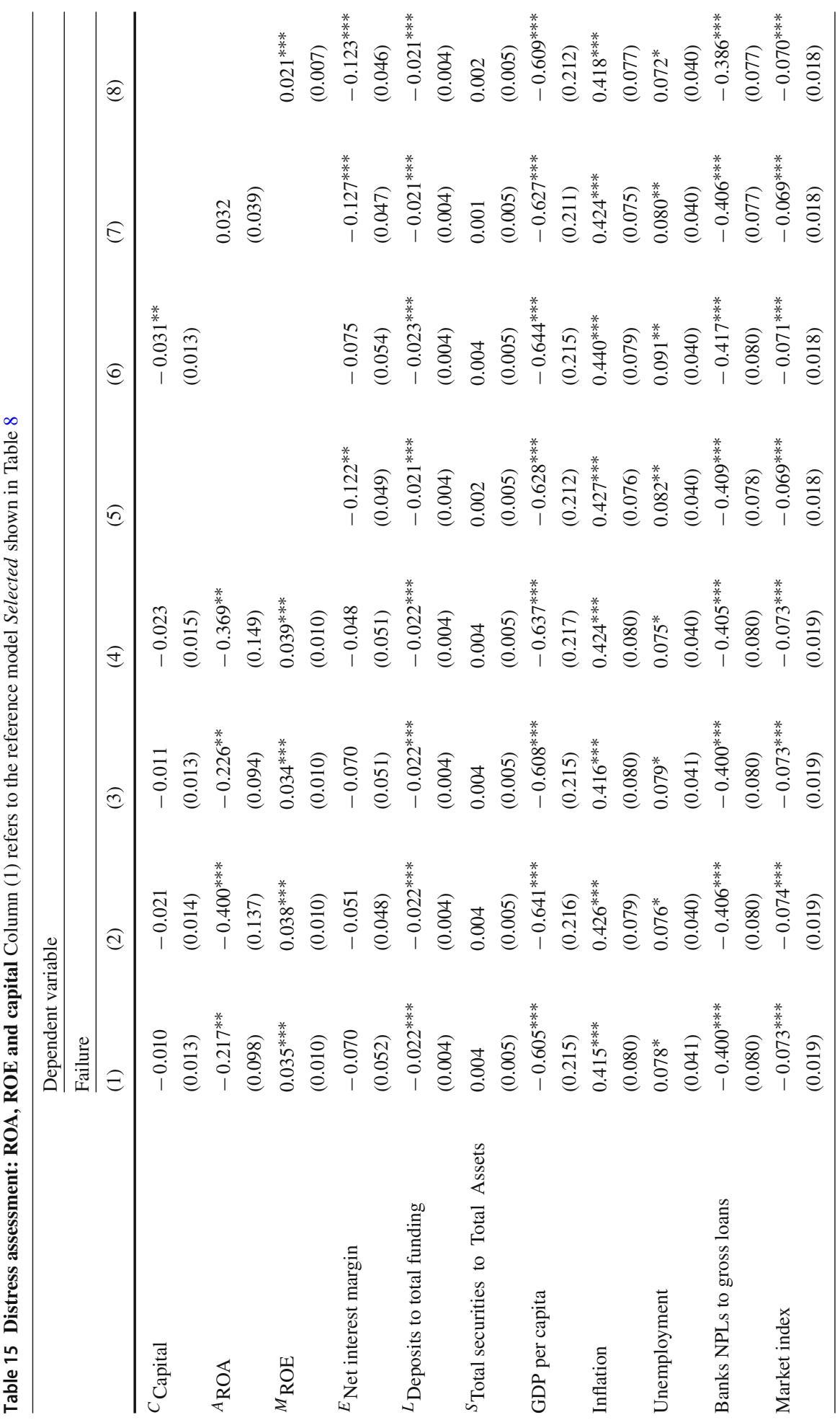




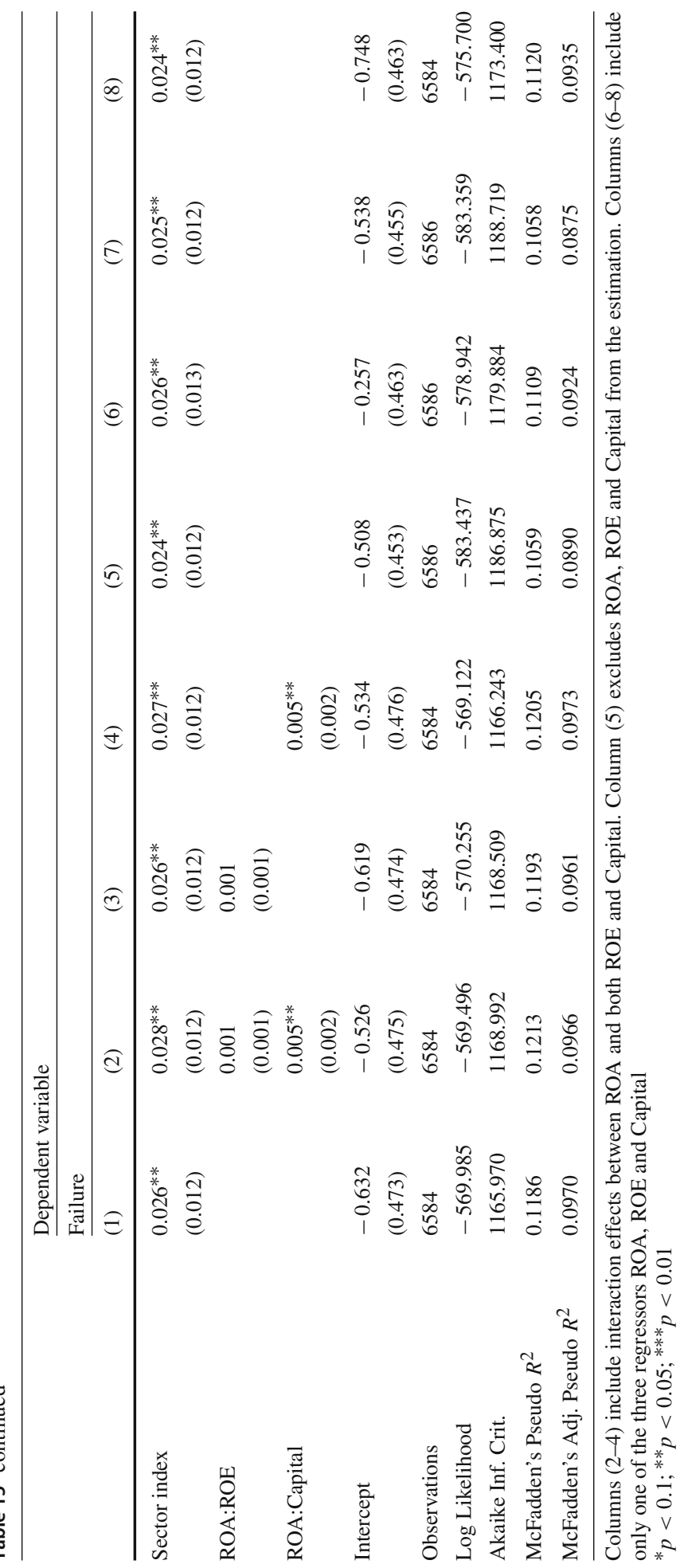


coherent between the Wholesale-oriented* model and the Wholesale-oriented* (Restricted) model.

This Appendix also presents variants of the risk assessment models seen in Sect. 5. In particular, Table 13 shows two alternative models in which instead of Capital (column 1), the Capital Adequacy is proxied by the Tier 1 (column 2) or the Total Capital Ratio (column 3). These two alternative models provide overall estimates in line with those discussed in column (1), thus supporting our main findings reported in the manuscript in Sect. 5 where we observe a marginal role of Capital in explaining the risk of distress. In addition, Table 14 reports the case in which Asset Quality is measured by the Impaired Loans to Gross Loans (column 2) or the Loan Loss Reserves to Impaired Loans (column 3), instead of ROA (column 1). Even in this case, a better quality of the assets is likely to reduce the likelihood of distress thus confirming our main findings. Both Tables 13 and 14 report, therefore, alternative models in which the risk of distress is assessed by means of accounting-based indicators that are better able to map CAMELS dimensions, but unfortunately with a more limited sample coverage. Although for these cases the sample size decreases substantially (thus further motivating the use of a rare-event logistic regression), still we notice that the main findings are largely confirmed.

The last Table 15 compares our "Selected" model (column 1) with three variants in which we include the interaction effects between ROA and both Capital and ROE. These are meant to explore potential interaction effects impacting ROA that may take place and go beyond a simple linear relationship with the other two variables. As shown in columns $2-4$, these additional regressors do not modify substantially the econometric estimation provided by the "Selected" model. Indeed, both the selected CAMELS variables and the Macro/Sector controls are largely confirmed in terms of significance, sign and magnitude of the corresponding betas. We also test if the main conclusions of the Selected model are confirmed once we rely on a more parsimonious setup. In column 5 we start by dropping the three regressors and we note that the remaining regressors have coefficients that are largely in line with those of the Selected model (column 1). In the following models (columns 6-8), instead, we include each regressor only one at a time. Note how, again, the set of the Macro/Sector controls remain very stable, and similarly the remaining CAMELS variables are largely unaffected. Specifically, capital (column 6) becomes significant but the sign and magnitude are very similar to those of the Selected model; and ii) ROE coefficient in column 8 is confirmed in terms of significance, sign, and magnitude.

\section{References}

Acharya, V., Engle, R., \& Richardson, M. (2012). Capital shortfall: A new approach to ranking and regulating systemic risks. American Economic Review, 102(3), 59-64.

Acharya, V., Pedersen, L., Philippon, T., \& Richardson, M. (2017). Measuring systemic risk. Review of Financial Studies, 1, 2-47.

Adrian, T., \& Brunnermeier, M. (2011). CoVaR. Working paper. Princeton University and Federal Reserve Bank of New York.

Anand, K., Gai, P., Kapadia, S., Brennan, S., \& Willison, M. (2013). A network model of financial system resilience. Journal of Economic Behavior and Organization, 85, 219-235.

Ayadi, R., Arbak, E., \& De Groen, P. W. (2011). Business models in European banking: A pre-and post-crisis screening. Center for European Policy Studies.

Ayadi, R., Arbak, E., \& De Groen, P. W. (2012). Regulation of European banks and business models: Towards a new paradigm? Centre for European Policy Studies.

Ayadi, R., \& De Groen, P. W. (2015). Banking business models 2015 Europe. Alphonse and Doriméne Desjardins International Institute for Cooperatives and International Research Centre on Cooperative Finance. 
BCBS. (2011). Global systemically important banks: Assessment methodology and the additional loss absorbency requirement. Bank of International Settlements.

BCBS. (2013). Capital requirements for banks' equity investments in funds. Bank of International Settlements.

Beltratti, A., \& Stultz, R. M. (2012). The credit crisis around the globe: Why did some banks perform better? Journal of Financial Economics, 105(1), 1-17.

Benston, G. J. (1994). Universal banking. Journal of Economic Perspectives, 8(3), 121-144.

Berger, A. N., \& Bouwman, C. H. S. (2013). How does capital affect bank performance during financial crises $\alpha$. Journal of Financial Economics, 109(1), 146-176.

Betz, F., Oprică, S., Peltonen, T. A., \& Sarlin, P. (2014). Predicting distress in European banks. Journal of Banking and Finance, 45, 225-241.

Blondel, V. D., Guillaume, J.-L., Lambiotte, R., \& Lefebvre, E. (2008). Fast unfolding of communities in large networks. Journal of Statistical Mechanics: Theory and Experiment, 2008(10), P10008+.

Brownlees, C., \& Engle, R. (2016). SRISK: A conditional capital shortfall index for systemic risk measurement. Review of Financial Studies (forthcoming).

Caliński, T., \& Harabasz, J. (1974). A dendrite method for cluster analysis. Communications in Statistics: Theory and Methods, 3(1), 1-27.

Casu, B., Girardone, C., \& Molyneux, P. (2015). Introduction to banking (2nd ed.). Pearson Education.

Chakraborty, T., Srinivasan, S., Ganguly, N., Bhowmick, S., \& Mukherjee, A. (2013). Constant communities in complex networks. Scientific Reports, 3, 1825.

Chiorazzo, V., Milani, C., \& Salvini, F. (2008). Income diversification and bank performance: Evidence from Italian banks. Journal of Financial Services Research, 33(3), 181-203.

Cole, R. A., \& White, L. J. (2012). Déjà vu all over again: The causes of US commercial bank failures this time around. Journal of Financial Services Research, 42(1-2), 5-29.

Cont, R., \& Minca, A. (2016). Credit default swaps and systemic risk. Annals of Operations Research, 247(2), 523-547.

Cornett, M. M., Ors, E., \& Tehranian, H. (2002). Bank performance around the introduction of a section 20 subsidiary. Journal of Finance, 57(1), 501-521.

Curi, C., Lozano-Vivas, A., \& Zelenyuk, V. (2015). Foreign bank diversification and efficiency prior to and during the financial crisis: Does one business model fit all? Journal of Banking and Finance, 61, S22-S35.

Demirgüç-Kunt, A., \& Detragiache, E. (2005). Cross-country empirical studies of survey. National Institute Economic Review, 192(1), 68-83.

Demirgüc-Kunt, A., \& Huizinga, H. P. (2010). Bank activity and funding strategies: The impact on risk and return. Journal of Financial Economics, 98(3), 626-650.

Dempster, A. P., Laird, N. M., \& Rubin, D. B. (1977). Maximum likelihood from incomplete data via the EM algorithm. Journal of the Royal Statistical Society Series B (Methodological), 39, 1-38.

Demyanyk, Y., \& Hasan, I. (2010). Financial crises and bank failures: A review of prediction methods. Omega, 38(5), 315-324.

DeYoung, R., \& Jang, K. Y. (2016). Do banks actively manage their liquidity? Journal of Banking and Finance, $66,143-161$.

DeYoung, R., \& Torna, G. (2013). Nontraditional banking activities and bank failures during the financial crisis. Journal of Financial Intermediation, 22(3), 397-421.

Dietrich, D., \& Vollmer, U. (2012). Are universal banks bad for financial stability? Germany during the world financial crisis. Quarterly Review of Economics and Finance, 52(2), 123-134.

Duan, L., Xu, L., Liu, Y., \& Lee, J. (2009). Cluster-based outlier detection. Annals of Operations Research, $168(1), 151-168$.

EBA. (2014). Guidelines: On common procedures and methodologies for the supervisory review and evaluation process (SREP). European Banking Authority.

Estrella, A., Park, S., \& Peristiani, S. (2000). Capital ratios as predictors of bank failure. Economic Policy Review, 6(2), 33-52.

Firth, D. (1993). Bias reduction of maximum likelihood estimates. Biometrika, 80(1), 27-38.

Flannery, M. J. (1998). Using market information in prudential bank supervision: A review of the US empirical evidence. Journal of Money, Credit and Banking, 30, 273-305.

Flori, A., Pammolli, F., Buldyrev, S. V., Regis, L., \& Stanley, H. E. (2019). Communities and regularities in the behavior of investment fund managers. Proceedings of the National Academy of Sciences, 116, 201802976.

Fortunato, S. (2010). Community detection in graphs. Physics Reports, 486(3-5), 75-174.

Georg, C.-P. (2013). The effect of the interbank network structure on contagion and common shocks. Journal of Banking and Finance, 37(7), 2216-2228.

González-Hermosillo, B. (1999). Determinants of ex-ante banking system distress: A macro-micro empirical exploration of some recent episodes. New York: International Monetary Fund. 
Gorton, G. B. (2010). Slapped by the invisible hand: The panic of 2007. Oxford: Oxford University Press.

Halkidi, M., Batistakis, Y., \& Vazirgiannis, M. (2001). On clustering validation techniques. Journal of Intelligent Information Systems, 17(2), 107-145.

Han, J., Kamber, M., \& Pei, J. (2011). Data mining: Concepts and techniques. Berlin: Elsevier.

Hawkins, J., \& Mihaljek, D. (2001). The banking industry in the emerging market economies: Competition, consolidation and systemic stability: An overview. BIS papers 4.

Honaker, J., \& King, G. (2010). What to do about missing values in time-series crosssection data. American Journal of Political Science, 54(2), 561-581.

Hoshi, T., \& Kashyap, A. (1999). The Japanese Banking Crisis: Where did it come from and how will it end? NBER Macroeconomics Annual, 14, 129-201.

Hryckiewicz, A., \& Kozłowski, Ł. (2017). Banking business models and the nature of financial crisis. Journal of International Money and Finance, 71, 1-24.

Huang, X., Zhou, H., \& Zhu, H. (2009). A framework for assessing the systemic risk of major financial institutions. Journal of Banking and Finance, 33, 2036-2049.

Ivashina, V., \& Scharfstein, D. (2010). Bank lending during the financial crisis of 2008. Journal of Financial Economics, 97(3), 319-338.

Jin, J. Y., Kanagaretnam, K., \& Lobo, G. J. (2011). Ability of accounting and audit quality variables to predict bank failure during the financial crisis. Journal of Banking and Finance, 35(11), 2811-2819.

Joseph, A., \& Bryson, N. (1997). W-efficient partitions and the solution of the sequential clustering problem. Annals of Operations Research, 74, 305-319.

Kashyap, A. K., Rajan, R., \& Stein, J. C. (2002). Banks as liquidity providers: An explanation for the coexistence of lending and deposit-taking. The Journal of Finance, 57(1), 33-73.

Khan, M. S., Scheule, H., \& Wu, E. (2016). Funding liquidity and bank risk taking. Journal of Banking and Finance, 82, 1-14.

Kick, T., \& Koetter, M. (2007). Slippery slopes of stress: Ordered failure events in German banking. Journal of Financial Stability, 3(2), 132-148.

Köhler, M. (2015). Which banks are more risky? The impact of business models on bank stability. Journal of Financial Stability, 16, 195-212.

Krause, A., \& Giansante, S. (2012). Interbank lending and the spread of bank failures: A network model of systemic risk. Journal of Economic Behavior and Organization, 83, 583-608.

Laeven, L., \& Valencia, F. (2010). Resolution of banking crises: The good, the bad, and the ugly (pp. 10-146). New York: International Monetary Fund.

Laeven, L. \& Valencia, F. (2012). Systemic banking crises database: An update (pp. 1-32).

Lancichinetti, A., Radicchi, F., Ramasco, J. J., \& Fortunato, S. (2011). Finding statistically significant communities in networks. PLOS ONE, 6(4), e18961.

Lozano-Vivas, A., \& Pasiouras, F. (2010). The impact of non-traditional activities on the estimation of bank effciency: International evidence. Journal of Banking and Finance, 34(7), 1436-1449.

Lucas, A., Schaumburg, J., \& Schwaab, B. (2018). Bank business models at zero interest rates. Journal of Business and Economic Statistics, 37, 542-555.

Ma, C., Blackwell, T., Boehnke, M., Scott, L. J., \& Investigators, G. (2013). Recommended joint and metaanalysis strategies for case-control association testing of single low-count variants. Genetic Epidemiology, 37(6), 539-550.

Manzaneque, M., GarcíA-Pérez-De-Lema, D., \& Antón Renart, M. (2015). Bootstrap replacement to validate the infuence of the economic cycle on the structure and the accuracy level of business failure prediction models. Journal of Forecasting, 34(4), 275-289.

Martin-Oliver, A., Ruano, S., \& Salas-Fumás, V. (2017). The fall of Spanish cajas: Lessons of ownership and governance for banks. Journal of Financial Stability, 33, 244-260.

Mergaerts, F., \& Vander Vennet, R. (2016). Business models and bank performance: A long-term perspective. Journal of Financial Stability, 22, 57-75.

Mousavi, M. M., \& Ouenniche, J. (2018). Multi-criteria ranking of corporate distress prediction models: Empirical evaluation and methodological contributions. Annals of Operations Research, 271(2), 853886.

Newman, M. E. J., \& Girvan, M. (2004). Finding and evaluating community structure in networks. Physical Review E Statistical, Nonlinear and Soft Matter Physics, 69(2 Pt 2), 16.

Ostry, J. D., Ghosh, A. R., Chamon, M., \& Qureshi, M. S. (2012). Tools for managing financial-stability risks from capital inflows. Journal of International Economics, 88(2), 407-421.

Ouenniche, J., Bouslah, K., Perez-Gladish, B., \& Xu, B. (2019). A new VIKOR-based in-sample-out-of-sample classifier with application in bankruptcy prediction. Annals of Operations Research. https://doi.org/10. 1007/s10479-019-03223-0. 
Paligorova, T., \& Santos, J. A. C. (2016). Banks' exposure to rollover risk and the maturity of corporate loans. Review of Finance, 21, rfw039.

Puliga, M., Flori, A., Pappalardo, G., Chessa, A., \& Pammolli, F. (2016). The accounting network: How financial institutions react to systemic crisis. PLOS ONE, 11(10), 1-14.

Roengpitya, R., Tarashev, N., \& Tsatsaronis, K. (2014). Bank business models. Basel: BIS.

Shleifer, A., \& Vishny, R. (2011). Fire sales in finance and macroeconomics. The Journal of Economic Perspectives, 25(1), 29-48.

Stiroh, K. J. (2004). Diversification in banking: Is noninterest income the answer? Journal of Money, Credit, and Banking, 36(5), 853-882.

Tan, P.-N., Steinbach, M., \& Kumar, V. (2006). Introduction to data mining (Vol. 1). Boston: Pearson.

Tirole, J. (2011). Illiquidity and all its friends. Journal of Economic Literature, 49(2), 287-325.

Traag, V. A., Krings, G., \& Van Dooren, P. (2013). Significant scales in community structure. Scientific Reports, 3, 2930.

van Dongen, S., \& Enright, A. J. (2012). Metric distances derived from cosine similarity and Pearson and Spearman correlations. CoRR arXiv:1208.3145.

van Oordt, M. R. C. (2013). Securitization and the dark side of diversification. Journal of Financial Intermediation, 23(2), 214-231.

Vazquez, F., \& Federico, P. (2015). Bank funding structures and risk: Evidence from the global financial crisis. Journal of Banking and Finance, 61, 1-14.

Wagner, W. (2010). Diversification at financial institutions and systemic crises. Journal of Financial Intermediation, 19(3), 373-386.

Wang, T. (2015). Competition and increasing returns to scale: A model of bank size. Economic Journal, 125(585), 989-1014.

Ward, J. (1963). Hierarchical grouping to optimize an objective function. Journal of the American Statistical Association, 58(301), 236-244.

Publisher's Note Springer Nature remains neutral with regard to jurisdictional claims in published maps and institutional affiliations. 